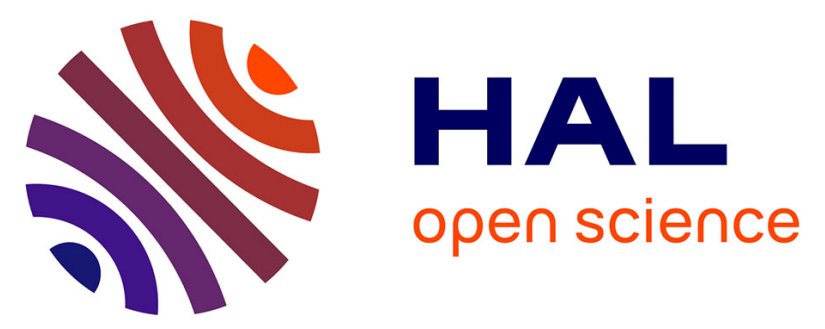

\title{
Synthesis, thermal, structural and linear optical properties of new glasses within the TeO2-TiO2-WO3 system
}

Mohammed Reda Zaki, David Hamani, Maggy Colas, Jean-René Duclere, Olivier Masson, Philippe Thomas

\section{To cite this version:}

Mohammed Reda Zaki, David Hamani, Maggy Colas, Jean-René Duclere, Olivier Masson, et al.. Synthesis, thermal, structural and linear optical properties of new glasses within the TeO2-TiO2-WO3 system. Journal of Non-Crystalline Solids, 2018, 484, pp.139-148. 10.1016/j.jnoncrysol.2018.01.034 . hal-01702013

\section{HAL Id: hal-01702013 \\ https://hal.science/hal-01702013}

Submitted on 17 Feb 2020

HAL is a multi-disciplinary open access archive for the deposit and dissemination of scientific research documents, whether they are published or not. The documents may come from teaching and research institutions in France or abroad, or from public or private research centers.
L'archive ouverte pluridisciplinaire HAL, est destinée au dépôt et à la diffusion de documents scientifiques de niveau recherche, publiés ou non, émanant des établissements d'enseignement et de recherche français ou étrangers, des laboratoires publics ou privés. 


\title{
Synthesis, thermal, structural and linear optical properties of new glasses within the $\mathrm{TeO}_{2}-\mathrm{TiO}_{2}-\mathrm{WO}_{3}$ system
}

Mohammed Reda ZAKI, David HAMANI*, Maggy DUTREILH-COLAS, Jean-René DUCLÈRE, Olivier MASSON and Philippe THOMAS

Laboratoire Science des Procédés Céramiques et de Traitements de Surface (SPCTS) - UMR 7315 CNRS, Université de Limoges, Centre Européen de la Céramique, 12 rue Atlantis, 87068 Limoges Cedex, FRANCE

* Corresponding author: David HAMANI, E-mail: david.hamani@unilim.fr

\begin{abstract}
.
The glass-forming domain and physical properties, namely, the density, thermal, structural and linear optical properties of new glasses within the $\mathrm{TeO}_{2}-\mathrm{TiO}_{2}-\mathrm{WO}_{3}$ system have been investigated. By means of micro-Raman spectroscopy, the structure of these glasses was examined based on a full-scale spectral decomposition. The optical transmission and refractive index dispersion were measured by UV-Vis-NIR spectroscopy and spectroscopic ellipsometry respectively. Consistent correlations were established between the structural and linear optical properties. Only minor structural modifications of the original $\mathrm{TeO}_{2}$-rich network are taking place upon adding $\mathrm{TiO}_{2}$ or $\mathrm{WO}_{3}$, suggesting the absence of $\mathrm{Te}-\mathrm{O}-\mathrm{Te}$ bond network depolymerization. Our results also suggest that, upon increasing $\mathrm{TiO}_{2}$ content, a phase separation occurs between amorphous $\mathrm{TeO}_{2}$-rich and amorphous $\mathrm{TiO}_{2}$-rich regions. We also argue that the structural trends upon adding $\mathrm{WO}_{3}$ evolve from uniformly dispersed $\mathrm{WO}_{6}$ octahedra (at low $\mathrm{WO}_{3}$ content) to amorphous $\mathrm{WO}_{3}$-like regions (at higher $\mathrm{WO}_{3}$ content) before the crystallization of $\gamma-\mathrm{WO}_{3}$ at $30 \mathrm{~mol} . \%$ of $\mathrm{WO}_{3}$. The compositional dependence of the refractive index and several optical constants (Urbach $E_{U}$ and dispersion $E_{d}$ energies, oxide ion polarizabilities) is highlighted. These glasses collectively exhibit high refractive indices in the order of $\sim 2.2$.
\end{abstract}




\section{Graphical abstract.}

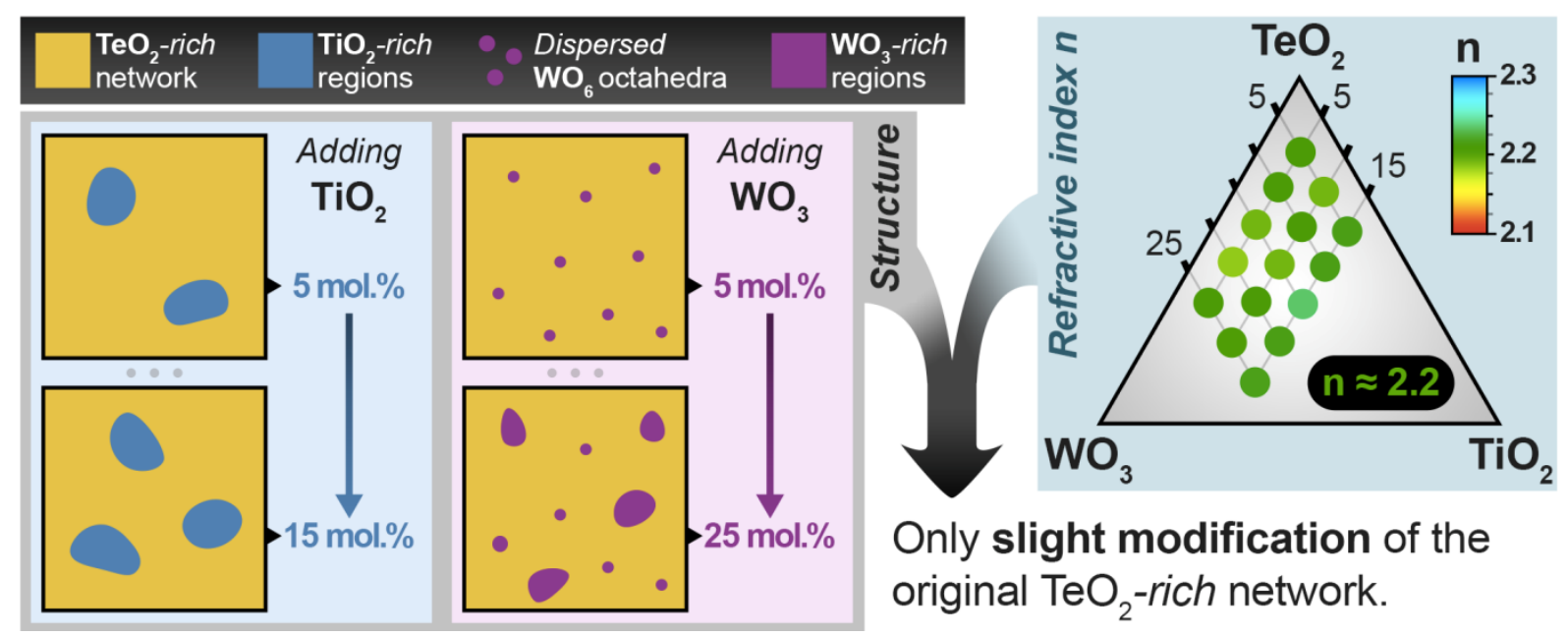

\section{Highlights.}

- New glass-forming domain within the $\mathrm{TeO}_{2}-\mathrm{TiO}_{2}-\mathrm{WO}_{3}$ system was determined.

- Relevant correlations between the structural and optical properties are established.

- Structural effects of $\mathrm{TiO}_{2}$ and $\mathrm{WO}_{3}$ are revealed and discussed in detail.

- The investigated glasses exhibit high refractive indices in the order of $\sim 2.2$.

\section{Keywords.}

Tellurite glasses; glass structure; Raman spectroscopy; linear optical properties. 


\section{Introduction.}

In the past two decades, tellurium oxide-based glasses have attracted a great deal of interest owing to their potential applications as fiber amplifiers and nonlinear optical devices [1-3]. They are still regarded as considerably promising optical materials thanks to, inter alia, remarkable optical properties, good thermal and chemical stabilities, and low glass transition temperatures [3]. The understanding of the origins behind the above set of physical properties is an ongoing subject matter in glass science. Therefore, a great deal of attention is still being devoted to establish the physical properties-structure relationships in these $\mathrm{TeO}_{2}$-based glasses.

Routinely, the structural description of $\mathrm{TeO}_{2}$-rich glasses is closely influenced by the study of the parent crystalline phases and pure $\mathrm{TeO}_{2}$ glass. Similarities between the pure $\mathrm{TeO}_{2}$ glass and the $\gamma-\mathrm{TeO}_{2}$ crystal structures were highlighted [4,5]. The latter is composed of $(i) \mathrm{TeO}_{4}$, or more precisely $\mathrm{TeO}_{3+1}$ distorted disphenoids with one $\mathrm{Te}-\mathrm{O}$ bond longer $(2.197 \AA)$ than the other three ones $(1.859,1.948$ and $2.019 \AA$ ) and the presence of a lone electron pair for each $\mathrm{Te}^{4+}$ cation constraining the short- and medium-range structure; (ii) asymmetric $\mathrm{Te}-\mathrm{O}-\mathrm{Te}$ bridges (1.859-2.197 $\AA$ ) and nearly symmetric ones (1.948-2.019 $\AA$ ). By comparing the $\gamma$ $\mathrm{TeO}_{2}$ compound and pure $\mathrm{TeO}_{2}$ glass using Raman spectroscopy ( $c f$. Fig. 3 in [4]), it has been argued that such nearly symmetric bridges constitute one of the main structural features of the $\mathrm{TeO}_{2}$ glass. Representing the near-medium-range structure, these bridges are responsible for the broad Raman band in the $400-550 \mathrm{~cm}^{-1}$ region.

From the optical properties viewpoint, the high linear and nonlinear optical indices of $\mathrm{TeO}_{2^{-}}$ based glasses have been associated with the presence of the $\mathrm{Te}^{4+}$ lone electron pair [6-10] and characteristic Te-O-Te bridges [3,11-13]. It has been shown that this inherently high optical response can be further improved upon adding transition metal oxides of empty d-orbital 
cations, such as titanium oxide $\mathrm{TiO}_{2}$ or tungsten oxide $\mathrm{WO}_{3}$ [14,15]. Moreover, it is well established that adding modifier oxides to $\mathrm{TeO}_{2}$ glass induces the structural transformation of $\mathrm{TeO}_{4}$ disphenoids into $\mathrm{TeO}_{3}$ trigonal pyramids, and therefore contributes to the short-range modification of the glass network $[3,16,17]$. This transformation is regarded as a "structural depolymerization" since it reduces the network crosslinking density by breaking Te-O-Te bridges. Moreover, it has been demonstrated that this transformation is accompanied with a decrease of the nonlinear optical properties $[3,18]$. By means of Raman spectroscopy, some authors claimed that adding $\mathrm{WO}_{3}$ induces this structural depolymerization in $\mathrm{TeO}_{2}$-based glasses $[19,20]$, which is not the case upon adding $\mathrm{TiO}_{2}$ [21-23].

Adding $\mathrm{TiO}_{2}$ to $\mathrm{TeO}_{2}$ allows to $(i)$ enhance the glass-forming ability and obtain homogeneous glasses in the $(100-\mathrm{x}) \mathrm{TeO}_{2}-\mathrm{xTiO}_{2}$ binary system with a glass-forming domain up to $\mathrm{x}=$ 18 mol.\%, and (ii) maintain the original structural organization of pure $\mathrm{TeO}_{2}$ glass [22,24]. Hence, $\mathrm{TiO}_{2}$-containing $\mathrm{TeO}_{2}$-based glasses are of special interest thanks to the positive role of $\mathrm{TiO}_{2}$ in conserving the glass network of pure $\mathrm{TeO}_{2}$ which contributes to the high linear and nonlinear optical properties $[15,18,23,25]$. Most of the preceding studies $[21,24,25]$ dealing with the structure of $\mathrm{TeO}_{2}-\mathrm{TiO}_{2}$ glasses supported the existence of $\mathrm{Te}-\mathrm{O}-\mathrm{Ti}$ bridges replacing the $\mathrm{Te}-\mathrm{O}-\mathrm{Te}$ ones in the glass network upon increasing $\mathrm{TiO}_{2}$ content. This idea is based on the unique phase from the $\mathrm{TeO}_{2}-\mathrm{TiO}_{2}$ system, $\mathrm{TiTe}_{3} \mathrm{O}_{8}$ [26], which features interconnected $\mathrm{TeO}_{4}$ and $\mathrm{TiO}_{6}$ polyhedra via nearly symmetric $\mathrm{Te}-\mathrm{O}-\mathrm{Ti}$ bridges with the following bond lengths: $1.867 \AA$ and $1.955 \AA$ A respectively.

With increasing $\mathrm{WO}_{3}$ content in binary $\mathrm{TeO}_{2}-\mathrm{WO}_{3}$ glasses, the thermal and optical properties are progressively improved [15,27]. These glasses have been extensively studied and the fact that no crystalline phase, i.e. no "parent crystalline model", has ever been identified in the binary $\mathrm{TeO}_{2}-\mathrm{WO}_{3}$ system led to considerable efforts for the understanding of their structural features. Most of these studies focused on the tungsten local environment (to demonstrate 
whether $\mathrm{WO}_{4}$ or $\mathrm{WO}_{6}$ polyhedra exist in the glass network) using IR and/or Raman spectroscopy techniques [28-31]; yet, despite many efforts, this basic information is still obscure and controversial [19,32-35]. In this paper, we will bring to light the local structure around $\mathrm{W}^{6+}$ cations in $\mathrm{WO}_{3}$-containing $\mathrm{TeO}_{2}$-based glasses. It was shown from previous works using Raman spectroscopy $[29,30,32]$ that compared with the Raman spectrum of $\mathrm{TeO}_{2}$ glass, three additional major bands (at $\sim 360,860$ and $925 \mathrm{~cm}^{-1}$ ) appear at the Raman spectra of $\mathrm{WO}_{3}$-containing $\mathrm{TeO}_{2}$-based glasses and their intensities increase upon adding $\mathrm{WO}_{3}$. It is generally agreed that the high-wavenumber band at $925 \mathrm{~cm}^{-1}$ originates from the stretching mode of the shortest W-O bonds. Sekiya et al. [29] suggested the growth of clusters of corner-sharing $\mathrm{WO}_{6}$ octahedra with increasing $\mathrm{WO}_{3}$ content in $\mathrm{TeO}_{2}-\mathrm{WO}_{3}$ glasses. It is important to recall here the existence of corner-sharing distorted $\mathrm{WO}_{6}$ octahedra in the $\gamma-\mathrm{WO}_{3}$ compound with twelve distinct W-O bond lengths ranging from 1.714 to $2.159 \AA$ [36].

Keeping the above facts in focus, we have embarked upon studying dual-transition metal oxide-containing $\mathrm{TeO}_{2}$-based glasses within the $(100-\mathrm{x}-\mathrm{y}) \mathrm{TeO}_{2}-\mathrm{xTiO}_{2}-\mathrm{yWO}_{3}$ ternary system (labeled TTxWy). To the best of our knowledge, only a handful studies have investigated compositions within the $\mathrm{TeO}_{2}-\mathrm{TiO}_{2}-\mathrm{WO}_{3}$ system. First, Safonov [37] attempted to determine its equilibrium and non-equilibrium phase diagram; Muñoz-Martín et al. [38] prepared and measured the structural and optical properties of the glass composition $80 \mathrm{TeO}_{2}-5 \mathrm{TiO}_{2}-$ $15 \mathrm{WO}_{3}$; and finally, a similar investigation was performed by Fares et al. [20] on the following quaternary composition: $(89-\mathrm{x}) \mathrm{TeO}_{2}-10 \mathrm{TiO}_{2}-\mathrm{xWO}_{3}-1 \mathrm{Nd}_{2} \mathrm{O}_{3}$.

The aim of the present paper is to report the glass-forming domain within the TTxWy system, the glasses' thermal characteristics, their structural features as probed by micro-Raman spectroscopy and finally, their linear optical properties from the optical transmission and spectroscopic ellipsometry measurements. The focus is laid on the evolution of these properties as a function of $\mathrm{TiO}_{2}$ and $\mathrm{WO}_{3}$ contents. 


\section{Experimental details.}

New glasses were prepared within the ternary TTxWy system by the conventional meltingquenching technique using $\alpha-\mathrm{TeO}_{2}(99.99 \%)$ and $\mathrm{WO}_{3}(99.8 \%)$ both from Alfa Aesar, and anatase $\mathrm{TiO}_{2}(99+\%)$ from Sigma-Aldrich. In appropriate proportions, the raw dried powders have been ground for 40 minutes using agate mortar and pestle, and melted in Pt crucibles at $850{ }^{\circ} \mathrm{C}$ for $1 \mathrm{~h}$ in air atmosphere. Under these experimental conditions, fifteen glass samples in the form of pellets were prepared from batches weighing $2 \mathrm{~g}$, stirred three times during melting (once every 15 minutes, in order to increase their homogeneity) and quenched from $850{ }^{\circ} \mathrm{C}$ into a brass ring put over a preheated brass block at $150{ }^{\circ} \mathrm{C}$. After cooling down from $150{ }^{\circ} \mathrm{C}$, glass pellets were systematically annealed at $15{ }^{\circ} \mathrm{C}$ below the glass transition temperature $\left(\mathrm{T}_{\mathrm{g}}\right)$ for $12 \mathrm{~h}$ at a rate of $2{ }^{\circ} \mathrm{C} / \mathrm{min}$ (during both heating and cooling) in order to release the mechanical stresses resulting from fast thermal quenching.

Moreover, to properly interpret the structural properties of TTxWy glasses, we have prepared pure $\mathrm{TeO}_{2}$ and binary $(100-\mathrm{x}) \mathrm{TeO}_{2}-\mathrm{xTiO}_{2}$ glasses (labeled TTx) by fast-quenching the melts from $850{ }^{\circ} \mathrm{C}$ down to approximately $-11^{\circ} \mathrm{C}$ (using an ice bath containing $\mathrm{NaCl}$ and ethanol) after 1 hour spent inside the furnace during which the melts were stirred three times.

To check the amorphous state of the samples, X-ray diffraction patterns were recorded from powder samples using Bruker D8 Advance diffractometer with Bragg-Brentano geometry (copper $\mathrm{K}_{\alpha 1}$ wavelength of $1.5406 \AA$, angular $2 \theta$ range of $10-70^{\circ}$ with a step of $0.02^{\circ}$ and $1 \mathrm{~s}$ per step). The glass samples were analyzed by energy dispersive X-ray microanalysis (EDS) using a Quanta FEG-450 scanning electron microscope. The elemental analysis results showed that the experimental glass compositions were in good agreement with the theoretical ones. The characteristic temperatures of glasses, namely the glass transition $\left(\mathrm{T}_{\mathrm{g}}\right)$ and onset 
crystallization $\left(\mathrm{T}_{\mathrm{O}}\right)$ temperatures were measured by heat flux differential scanning calorimetry (DSC) using NETZSCH STA 449 F3 Jupiter equipment. About $25 \pm 5$ mg of glass fragments were put into Pt pans, and the measurements were performed under $\mathrm{N}_{2}$ atmosphere between room temperature and $720{ }^{\circ} \mathrm{C}$ at a heating rate of $10{ }^{\circ} \mathrm{C} / \mathrm{min}$. Densities of glass powder samples $(150 \pm 20 \mathrm{mg})$ were measured by helium pycnometry using Accupyc II 1340 pycnometer from Micromeritics.

The Raman spectra of the obtained glass samples were recorded at $514 \mathrm{~nm}$ using T64000 Horiba Jobin-Yvon spectrophotometer operating in triple subtractive configuration (1800 $\mathrm{gr} / \mathrm{mm}$ ) associated to a liquid nitrogen-cooled CCD detector. The Raman spectra were recorded in the $15-1100 \mathrm{~cm}^{-1}$ wavenumber range while focusing the laser beam (exposure time of 10 seconds) at a depth of approximately $2 \mu \mathrm{m}$ from the top surface of the glass pellets. In each glass sample, three Raman spectra have been recorded from three different spots. The excellent agreement within each set of spectra demonstrates high degrees of topological homogeneity within the samples. As a reliable approach to study the compositional dependence of the Raman spectra, no baseline correction treatments were carried out on any of the measured Raman spectra, and the as-recorded intensities of each spectrum were divided by its total area. Using Focus 1.0 program [39], the total-area averaged Raman spectra were decomposed in the entire wavenumber range (15-1100 $\left.\mathrm{cm}^{-1}\right)$ using a log-normal distribution for the boson peak and twelve Gaussian functions for the rest of the wavenumber range. The calculated spectra are considered to match to the experimental ones with chi-square reliability values less than 0.05 .

To evaluate the optical transmission of TTxWy glasses, we measured the UV-Vis-NIR spectra from double side polished pellets of $1.44-1.47 \mathrm{~mm}$ in thickness over a wide wavelength range from 300 to $3300 \mathrm{~nm}$ using the Varian Cary 5000 spectrophotometer. Using the same samples, the refractive index dispersion was recorded by spectroscopic ellipsometry using a 
phase-modulated ellipsometer (Horiba Jobin-Yvon UVISEL) with a fixed $60^{\circ}$ incidence angle.

\section{Results and discussion.}

\subsection{Glass-forming domain}

The amorphous state of TTxWy samples was checked by X-ray powder diffraction in order to determine the glass-forming domain shown in Fig. 1(a). It extends from $x=5$ to 15 mol.\% in $\mathrm{TiO}_{2}$ and $\mathrm{y}=5$ to $25 \mathrm{~mol} . \%$ in $\mathrm{WO}_{3}$. In total, fifteen melt compositions have yielded yellowish-transparent glasses that shifted to honey-brown with increasing $\mathrm{WO}_{3}$ content and remained practically unchanged upon adding $\mathrm{TiO}_{2}(c f$. Fig. 1(b)).

Crystals of $\gamma-\mathrm{WO}_{3}$ compound [36,40] are detected in TTxW30 samples. The corresponding peaks become sharper and more intense upon adding $\mathrm{TiO}_{2}$, suggesting an increase of the number and/or average size of $\mathrm{WO}_{3}$ crystallites. At $20 \mathrm{~mol} . \%$ of $\mathrm{TiO}_{2}$, crystals of rutile $\mathrm{TiO}_{2}$ phase are detected in TT20Wy samples without any trace of crystallizing $\mathrm{TiTe}_{3} \mathrm{O}_{8}$ or anatase $\mathrm{TiO}_{2}$ phases.

\subsection{Density and thermal properties}

The densities and thermal characteristics of TTxWy glasses are jointly listed in Table 1. Since very close trends of these properties are observed upon adding $\mathrm{TiO}_{2}\left(\right.$ or $\left.\mathrm{WO}_{3}\right)$ at different $\mathrm{WO}_{3}\left(\right.$ or $\mathrm{TiO}_{2}$ ) contents, we suggest to consider TTxW5 and TT5Wy sets of samples for the sake of simplicity. The density increases with addition of $\mathrm{WO}_{3}$ by approximately $6 \%$ from

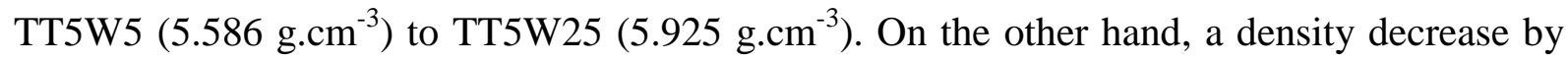




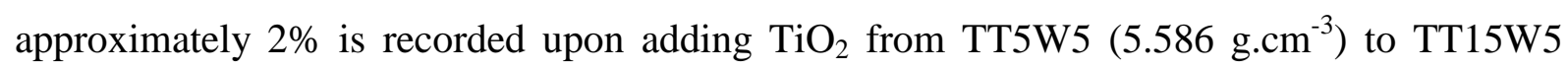

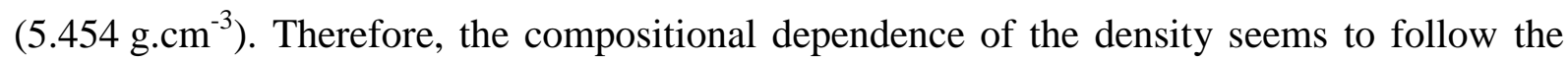
additive density rule: densities of raw oxides $\mathrm{TiO}_{2}, \mathrm{TeO}_{2}$ and $\mathrm{WO}_{3}$ are respectively 3.90, 6.13 and $7.16 \mathrm{~g} . \mathrm{cm}^{-3}$. The density evolutions in TTxWy glasses are logically assigned to the higher molar mass of $\mathrm{WO}_{3}\left(231.8\right.$ g.mol$\left.{ }^{-1}\right)$ and lower molar mass of $\mathrm{TiO}_{2}\left(79.9\right.$ g.mol $\left.{ }^{-1}\right)$ than that of $\mathrm{TeO}_{2}\left(159.6\right.$ g.mol$\left.{ }^{-1}\right)$.

The glass transition temperature $\mathrm{T}_{\mathrm{g}}$ in $\mathrm{TTxWy}$ glasses increases linearly upon adding either $\mathrm{TiO}_{2}$ or $\mathrm{WO}_{3}\left(\mathrm{~T}_{\mathrm{g}(\min )}=328{ }^{\circ} \mathrm{C}\right.$ and $\left.\mathrm{T}_{\mathrm{g}(\max )}=426{ }^{\circ} \mathrm{C}\right)$. It increases by $\sim 16 \%$ from TT5W5 $(328$ $\left.{ }^{\circ} \mathrm{C}\right)$ to TT15W5 $\left(380{ }^{\circ} \mathrm{C}\right)$ and by $\sim 15 \%$ from TT5W5 $\left(328^{\circ} \mathrm{C}\right)$ to TT5W25 $\left(376{ }^{\circ} \mathrm{C}\right)$. A step increase by $10 \mathrm{~mol} . \%$ in $\mathrm{TiO}_{2}$ induced an overall rise of $\mathrm{T}_{\mathrm{g}}$ that is twice more consequential (increase by $\sim 50{ }^{\circ} \mathrm{C}$ ) than in the case of $\mathrm{WO}_{3}$ (increase by $\sim 25^{\circ} \mathrm{C}$ ).

It is worth pointing out that the thermal stabilities $\left(\Delta \mathrm{T}=\mathrm{T}_{\mathrm{O}}-\mathrm{T}_{\mathrm{g}}\right)$ which reflect the ability of the glass network to resist against devitrification upon heating above $\mathrm{T}_{\mathrm{g}}$, are fairly moderate among TTxWy glasses $\left(\Delta \mathrm{T}_{\min }=31^{\circ} \mathrm{C}\right.$ and $\left.\Delta \mathrm{T}_{\max }=57{ }^{\circ} \mathrm{C}\right)(c f$. Table 1 and Fig. 2). These thermal stabilities might represent a limiting factor for the use of these glasses in the optical fiber technology, for which as an "experimental standard", a minimum value of $100{ }^{\circ} \mathrm{C}$ is needed. Adding $\mathrm{TiO}_{2}$ induces an increase of $\Delta \mathrm{T}$ from $\mathrm{TT} 5 \mathrm{Wy}$ to TT10Wy glasses before a decrease in TT15Wy glass samples. It seems though that $\Delta \mathrm{T}$ is marginally improved with continuous increase in $\mathrm{WO}_{3}$ content.

\subsection{Structural properties}

\subsubsection{Structural effect of adding $\mathrm{TiO}_{2}$}


According to Dietzel's cationic field strength theory [41,42], one of the classical structural theories of glass formation, the concept of field strength (FS) represents the interaction of forces between cations and anions during the melt cooling. It is expressed as follows: $\mathrm{FS}=$ $\mathrm{Z}_{\mathrm{c}} / a^{2}$, where $\mathrm{Z}_{\mathrm{c}}$ is the charge number of the cation, and $a$ is the sum of ionic radii of the cation and anion. In binary oxide melts where the two constituent cations have very close FS values, a slow cooling rate (towards crystallization) is expected to lead to a solid solution type of organization in the crystal; whereas faster cooling/quenching rates (towards glass formation) would result in a phase separation between the two pure oxide phases. We calculated the FS values while considering $\mathrm{O}^{2-}, \mathrm{Te}^{4+}$ and $\mathrm{Ti}^{4+}$ ions to be two-fold, four-fold and six-fold coordinated respectively and having the following ionic radii: $1.35 \AA, 0.66 \AA$ and $0.605 \AA$ [43]. It is very important to highlight that $(i)$ the FS values for $\mathrm{Te}^{4+}(0.990)$ and $\mathrm{Ti}^{4+}(1.047)$ cations are very close, and that (ii) the only reported crystal compound from binary $\mathrm{TeO}_{2^{-}}$ $\mathrm{TiO}_{2}$ system, namely $\mathrm{TiTe}_{3} \mathrm{O}_{8}$ [26], is in fact a solid solution of $\mathrm{TiO}_{2}$ in $\mathrm{TeO}_{2}$ with a ratio of 1:3 respectively. Therefore, since the FS theory proves to be valid for the equilibrium $\mathrm{TeO}_{2^{-}}$ $\mathrm{TiO}_{2}$ system, one would expect that it would successfully predict the structure of binary TTx glasses as well. In other words, a phase separation within the glass network could be predicted and thus resulting in $\mathrm{TeO}_{2}$-rich and $\mathrm{TiO}_{2}$-rich regions. The limited experimentally-detected glass forming ability upon adding $\mathrm{TiO}_{2}$ (maximum of $\mathrm{x}=15$ mol. $\%$ in both $\mathrm{TTx}$ and TTxWy glasses) supports this predicted heterogeneous nature of their glass networks.

To elucidate the structural effect of adding $\mathrm{TiO}_{2}$, we first examine the TTx system before rushing into the more complicated TTxWy system given that: (i) identical glass forming ability upon adding $\mathrm{TiO}_{2}$ (limited to $15 \mathrm{~mol} . \%$ ) is found in TTx and TTxWy systems; (ii) the close force constants of $\mathrm{Te}-\mathrm{O}$ and $\mathrm{Ti}-\mathrm{O}$ bonds [22] would likely cause strong overlapping of their corresponding bands in the Raman spectra of $\mathrm{TiO}_{2}$-containing $\mathrm{TeO}_{2}$-based glasses.

- $\operatorname{Binary}(100-x) \mathrm{TeO}_{2}-x \mathrm{TiO}_{2}$ glasses (TTx glasses) 
The recorded Raman spectra from TTx glasses are presented in Fig. 3. They show an intensity increase of bands at $\sim 445, \sim 615$ and $\sim 850 \mathrm{~cm}^{-1}$ upon adding $\mathrm{TiO}_{2}$ from 2.5 to $15 \mathrm{~mol} \%$, and an intensity decrease of bands at $\sim 660$ and $\sim 730 \mathrm{~cm}^{-1}$. The assignment of these Raman bands, is given in Table 2; particularly, that of Ti-O vibrations is based on the refs [44-46]. Since the bands at $\sim 660$ and $\sim 730 \mathrm{~cm}^{-1}$ are associated with $\mathrm{Te}-\mathrm{O}$ vibrations in $\mathrm{TeO}_{4}$ and $\mathrm{TeO}_{3}$ units respectively, their decreasing number with addition of $\mathrm{TiO}_{2}$ suggests that no structural depolymerization takes place in TTx glasses (as opposed to a striking depolymerization observed in $\mathrm{TeO}_{2}-\mathrm{Tl}_{2} \mathrm{O}$ glassy system for example [47]). It appears that this decreasing number of $\mathrm{TeO}_{4}$ and $\mathrm{TeO}_{3}$ units is compensated by an increasing number of $\mathrm{Ti}-\mathrm{O}-\mathrm{Ti}$ bridges (at $\sim 445 \mathrm{~cm}^{-1}$ and $\sim 615 \mathrm{~cm}^{-1}$ ) and terminal Ti-O bonds (at $\sim 850 \mathrm{~cm}^{-1}$ ). The presence of Ti-O$\mathrm{Ti}$ and $\mathrm{Ti}-\mathrm{O}$ linkages in the glass network is supported by the features of the Raman spectrum of nano-rutile $\mathrm{TiO}_{2}$ ( $c f$. inset in Fig. 3). As highlighted in the inset, the shoulder at $\sim 850 \mathrm{~cm}^{-1}$ is only detected from the few-nanometer-sized rutile $\mathrm{TiO}_{2}$ samples ( $c f$. spectrum in orange) and absent in the bulk sample (spectrum in black). It is associated with the antisymmetric stretching vibrations of $\mathrm{Ti}-\mathrm{O}$ bonds from distorted $\mathrm{TiO}_{6-\mathrm{x}}$ polyhedra at the surface of $\mathrm{TiO}_{2}$ nanoparticles $[44,45]$. Therefore, it seems that amorphous "rutile-like" $\mathrm{TiO}_{2}$-rich regions (of few nanometers) exist separately from the $\mathrm{TeO}_{2}$-rich network and their number increases with increasing $\mathrm{TiO}_{2}$ content from 2.5 to $15 \mathrm{~mol} \%$ in TTx glasses before an extensive growth takes place via the crystallization of rutile $\mathrm{TiO}_{2}$ at 20 mol.\% detected by X-ray powder diffraction.

A thorough search of the relevant literature yielded only a single and unanimously accepted structural description of the $\mathrm{TiO}_{2}$-containing $\mathrm{TeO}_{2}$-based glasses $[21,24,25,48,49]$ (and above all, the binary $\mathrm{TeO}_{2}-\mathrm{TiO}_{2}$ glasses $\left.[21,22,24]\right)$. This description is based on the participation of symmetric $\mathrm{Te}-\mathrm{O}-\mathrm{Ti}$ bridges in the glass network by replacing the original $\mathrm{Te}-\mathrm{O}-\mathrm{Te}$ ones. It was largely supported by the fact that these two bridges are chemically indiscernible, thus 
explaining the insignificant changes in the Raman spectra upon adding $\mathrm{TiO}_{2}$. However, as expressed in the following, we provide here a new viewpoint regarding this description.

Let us consider the symmetric $\mathrm{Te}-\mathrm{O}-\mathrm{Ti}$ bridges. The latter exist in the $\mathrm{TiTe}_{3} \mathrm{O}_{8}$ compound, and their symmetric stretching vibrational mode gives rise to the most intense band at $\sim 477$ $\mathrm{cm}^{-1}$ (cf. Fig. 3). If those symmetric Te-O-Ti bridges truly constituted the backbone of the structural network in TTx glasses, then we would have recorded a significant intensity increase at $\sim 477 \mathrm{~cm}^{-1}$ upon adding $\mathrm{TiO}_{2}$, which is clearly not the case when analyzing the spectra of TTx glasses. Therefore, since the number of Te-O-Ti bridges does not increase with addition of $\mathrm{TiO}_{2}$ and since the vibrational signature of nano-rutile $\mathrm{TiO}_{2}$ is observed, we propose that the structure of the glass network is made of "rutile-like" $\mathrm{TiO}_{2}$-rich regions in a $\mathrm{TeO}_{2}$-rich network as initially predicted using the field strength theory.

\section{- Ternary (100-x-y) $\mathrm{TeO}_{2}-x \mathrm{TiO}_{2}-y \mathrm{WO}_{3}$ glasses (TTxWy glasses)}

The Raman spectra of TTxWy glasses upon adding $\mathrm{TiO}_{2}$ are given in Fig. 4. A similar spectral evolution, i.e. intensity increase at $\sim 445, \sim 615$ and $\sim 850 \mathrm{~cm}^{-1}$ is observed from TTxWy glasses. Because of two overlapping bands at $\sim 860$ and $\sim 925 \mathrm{~cm}^{-1}$ due to vibrating $\mathrm{W}-\mathrm{O}$ bonds, the intensity increase at $\sim 850 \mathrm{~cm}^{-1}$ is less noticeable than from TTx glasses. It is important to recall here that, same as in binary TTx, the glass-forming domain in TTxWy is limited to only $15 \mathrm{~mol} . \%$ of $\mathrm{TiO}_{2}$. Hence, it seems that the influence of $\mathrm{TiO}_{2}$ on a network of either pure $\mathrm{TeO}_{2}$ (TTx system) or $\mathrm{WO}_{3}$-containing $\mathrm{TeO}_{2}$ (TTxWy system) is indifferent.

From the above discussion, we argue that a phase separation between amorphous $\mathrm{TeO}_{2}$-rich and amorphous "rutile-like" $\mathrm{TiO}_{2}$-rich regions occurs in $\mathrm{TiO}_{2}$-containing $\mathrm{TeO}_{2}$-based glasses. This interpretation is shared with a previous study [50] that predicted phase separation in the $75 \mathrm{TeO}_{2}-25 \mathrm{TiO}_{2}$ glass composition. 


\subsubsection{Structural effect of adding $\mathrm{WO}_{3}$}

The evolving features of the Raman spectra of TTxWy glasses with increasing $\mathrm{WO}_{3}$ content (Fig. 5) are in agreement with the reported studies on $\mathrm{WO}_{3}$-containing $\mathrm{TeO}_{2}$-based glasses by Raman spectroscopy $[19,29,35]$. These studies have shown that three additional bands (at $\sim 360, \sim 860$ and $\sim 925 \mathrm{~cm}^{-1}$ ) emerge at the Raman spectra and increase in intensity upon adding $\mathrm{WO}_{3}$.

Since the same structural evolutions were observed from TT5Wy, TT10Wy and TT15Wy samples, we suggest to focus on the set of TT5Wy for the sake of simplicity (Fig. 6). The assignment of the Raman bands is given in Table 2. The origin of bands E-J $\left(425-772 \mathrm{~cm}^{-1}\right)$ is supported by previous pioneer works on the vibrational and structural properties of the three $\mathrm{TeO}_{2}$ polymorphs ( $\alpha$ [51], $\beta$ [51] and $\gamma$ [4]). The rest of the identified Raman bands (C-D extending from 230 to $351 \mathrm{~cm}^{-1}$ and K-M from 820 to $\sim 934 \mathrm{~cm}^{-1}$ ) are associated with the vibrational response of distorted $\mathrm{WO}_{6}$ octahedra. The basis of the previous assignment is a bilateral analysis of the vibrational (Raman spectra) vs. structural features that we conducted on a large number of tungsten-containing oxides (metal tungstates for the most part). A similar approach has been previously undertaken on few tungstates by Sekiya et al. [29]. In the low-wavenumber region, the band $\mathrm{B}$ is attributed to intra-chain vibrations of Te-Te bonds (as in amorphous metallic trigonal Te [52]) and the band A (boson peak) is linked to the glass network at medium-range scale $[53,54]$.

For the spectral decomposition, we used a conventional fitting technique based on the addition of bands of which the position (wavenumber), width (more precisely the full width at half maximum, FWHM) and intensity can be either assigned fixed values or free (unconstrained) in order to consistently investigate all the glass spectra. In wavenumber regions where band shift and/or broadening are observed with increasing $\mathrm{WO}_{3}$ content (at constant $\mathrm{TiO}_{2}$ ), we kept the introduced function's wavenumber and/or FWHM respectively 
parameter-free. Thus, the bands $\mathrm{A}, \mathrm{H}$ and $\mathrm{M}$ were fully unconstrained, while bands $\mathrm{F}$ and $\mathrm{L}$ were introduced with fixed FWHM values and bands D and $\mathbf{J}$ with fixed wavenumbers values. The remaining bands $\mathrm{B}, \mathrm{C}, \mathrm{E}, \mathrm{G}, \mathrm{I}$ and $\mathrm{K}$ were introduced with fixed wavenumber and FWHM values.

As can be seen in Fig. 6, the features shown by the set of vibrational modes of Te-O bonds in asymmetric and nearly symmetric Te-O-Te bridges (bands E-J), compared to those of pure $\mathrm{TeO}_{2}$ glass, have only been slightly modified in terms of their bands' profiles, positions and intensity ratios upon increasing $\mathrm{WO}_{3}$ content. The key information with respect to the crosslinking of Te-O-Te bridges within the glass network is contained within the 400-550 $\mathrm{cm}^{-1}$ range (bands $\mathrm{E}$ and $\mathrm{F}$ ). In this region, the intensity barely decreases suggesting that the network of Te-O-Te bridges has been only slightly modified. Thus, it seems that adding $\mathrm{WO}_{3}$ does not considerably alter the original structural features within the network of $\mathrm{Te}-\mathrm{O}-\mathrm{Te}$ bridges.

In order to exclude the compositional effect, we have calculated the normalized intensities of the decomposed bands $\mathrm{E}-\mathrm{H}$ by dividing their areas by $\mathrm{TeO}_{2}$ molar content (attributed to vibrations of $\mathrm{Te}-\mathrm{O}$ bonds) and those of the bands $\mathrm{D}$ and $\mathrm{K}-\mathrm{M}$ by $\mathrm{WO}_{3}$ molar content (attributed to vibrations of $\mathrm{W}-\mathrm{O}$ bonds). It should be noted that this approach of normalization to the composition yields dissimilar band evolutions compared to the total-area averaged spectra ( $c f$. bands $\mathrm{D}, \mathrm{L}$ and $\mathrm{M}$ for example). The compositional-dependence of the normalized intensities of bands D, E-H and $\mathrm{K}-\mathrm{M}$ in TT5Wy glasses is plotted in Fig. 7.

Regarding the $\mathrm{TeO}_{2}$-rich network, the evolution of the normalized intensities of bands $\mathrm{E}-\mathrm{G}$ suggests a minor structural modification of the glass network since the bands $F$ and $G$ seem to be unaffected upon adding $\mathrm{WO}_{3}$. The band $\mathrm{E}$ shows a moderate increase of its normalized intensity that might be due to a slightly increasing number of nearly symmetric $\mathrm{Te}-\mathrm{O}-\mathrm{Te}$ bridges. Given the relatively insignificant modification of the crosslinked network of Te-O- 
Te bridges, and in agreement with the forthcoming discussion on $\mathrm{WO}_{3}$ effect, we assign the increasing intensity of bands $\mathrm{I}$ and $\mathrm{J}$ (attributed to vibrations of $\mathrm{Te}-\mathrm{O}$ and $\mathrm{W}-\mathrm{O}$ bonds) to an increase of $\mathrm{W}-\mathrm{O}-\mathrm{W}$ bridges as in $\gamma-\mathrm{WO}_{3}$. Since these two bands are highly interactive via overlapping, we intentionally omitted their compositional evolutions from Fig. 7.

Let us know consider the Raman bands $\mathrm{D}, \mathrm{K}, \mathrm{L}$ and $\mathrm{M}$ associated with distorted $\mathrm{WO}_{6}$ octahedra. The normalized intensity decrease of the bands $\mathrm{D}, \mathrm{L}$ and $\mathrm{M}$ upon increasing $\mathrm{WO}_{3}$ content implies that less and less short $\mathrm{W}-\mathrm{O}$ bonds (shorter than $\sim 1.80 \AA$ ) exist in the network. In other words, less and less uniformly dispersed $\mathrm{WO}_{6}$ octahedra are directly connected to the glass network. In fact, the normalized intensity increase of the band $\mathrm{K}$ suggests a possible increase of the number of corner-sharing $\mathrm{WO}_{6}$ octahedra as in $\gamma-\mathrm{WO}_{3}$ (also supported by Sekiya et al. [29] in $\mathrm{TeO}_{2}-\mathrm{WO}_{3}$ glasses). It is important to stress that given the small size and minor contribution of the band $\mathrm{K}$, the previous discussion on its evolution is more of a hypothetical nature. Therefore, it seems that the intensity increase of the large shoulder within the $700-820 \mathrm{~cm}^{-1}$ range (Fig. 5) arises from vibrating $\mathrm{W}-\mathrm{O}-\mathrm{W}$ bridges in the continuously growing amorphous $\mathrm{WO}_{3}$-like regions upon increasing $\mathrm{WO}_{3}$ content. It is important to recall that within this wavenumber range, symmetric and asymmetric stretching vibrational modes of $\mathrm{W}-\mathrm{O}-\mathrm{W}$ bridges are expected in $\gamma-\mathrm{WO}_{3}$ at $\sim 715$ and $820 \mathrm{~cm}^{-1}$ respectively ( $c f$. Raman spectrum in Fig. 5). Moreover, the weak intensity increase in the 200$300 \mathrm{~cm}^{-1}$ range is probably due to bending vibrational modes of $\mathrm{WO}_{6}$ octahedra as observed in $\gamma-\mathrm{WO}_{3}$. These findings are in agreement with XPS results [55] showing a decrease of O1s binding energy in $(100-\mathrm{x}) \mathrm{TeO}_{2}-\mathrm{xWO}_{3}$ glasses from $\mathrm{x}=5$ to $30 \mathrm{~mol} . \%$, which indicates that oxide ions are more likely to participate within the glass network as bridging ones.

Concerning the evolution of the boson peak (band A), the position of its maximum intensity insignificantly red-shifts accompanied with an intensity decrease with addition of $\mathrm{TiO}_{2}$ or $\mathrm{WO}_{3}$ contents ( $c f$. Figs. 4 and 6). According to previous works [56,57], the evolution of boson 
peak's position and intensity in TTxWy glasses could suggest a slight crosslinking density increase in the glass network at the medium-range scale. This behavior is in agreement with the continuous increase of the glass transition temperature upon adding $\mathrm{TiO}_{2}$ or $\mathrm{WO}_{3}$.

Since the same compositional evolutions of structural features as revealed by micro-Raman spectroscopy are observed upon increasing $\mathrm{WO}_{3}$ content at different $\mathrm{TiO}_{2}$ concentrations with no further emerging bands (Fig. 5), it seems unlikely that $\mathrm{Ti}-\mathrm{O}-\mathrm{W}$ bridges participate in the crosslinking within the glass network.

From the above discussion, we argue that unlike the peculiar structural effect of $\mathrm{TiO}_{2}$ promoting a phase separation within the amorphous glass network, the incorporation of $\mathrm{WO}_{3}$ results in uniformly dispersed (throughout the glass network) $\mathrm{WO}_{6}$ octahedra which tend to form amorphous $\mathrm{WO}_{3}$-like regions before ending with crystallized $\gamma-\mathrm{WO}_{3}$ at $30 \mathrm{~mol} . \%$. This might explain why the addition of $\mathrm{TiO}_{2}$ and $\mathrm{WO}_{3}$ results in relatively moderate thermal stabilities of TTxWy glasses.

\subsection{Linear optical properties}

\subsubsection{Refractive index, optical band gap and Urbach energies by UV-Vis-NIR optical transmission}

The optical transmission spectra of 14 out of $15 \mathrm{TTxWy}$ glass samples show a transparency over $75 \%$ in the $800-2600 \mathrm{~nm}$ range (cf. Fig. 8). Only the sample TT15W25 showed a markedly lower transparency of $\sim 68 \%$ in this region. This can be related to its peculiar composition (richest in both $\mathrm{TiO}_{2}$ and $\mathrm{WO}_{3}$ oxides) at the boundary of the glass-forming domain. The large absorption band onsetting at $\sim 2800 \mathrm{~nm}$ is recorded in all of the samples. It corresponds to the stretching mode of bound hydroxyl groups $(\mathrm{R}-\mathrm{OH})$, and both symmetric 
and asymmetric stretching modes of $\mathrm{H}_{2} \mathrm{O}$ molecules [58]. Similar evolutions are generally observed upon adding $\mathrm{TiO}_{2}$ (or $\mathrm{WO}_{3}$ ) at constant $\mathrm{WO}_{3}$ (or $\mathrm{TiO}_{2}$ ) content. Therefore, in the following, we only consider TTxW5 and TT5Wy sets when discussing the effects of $\mathrm{TiO}_{2}$ and $\mathrm{WO}_{3}$ on the optical properties.

The UV absorption edge red-shifts with increasing $\mathrm{WO}_{3}$ content (cf. Fig. 8 (a) for TT5Wy glasses). Likewise, a minor red-shift is observed within a narrower wavelength range (400$475 \mathrm{~nm}$ ) upon adding $\mathrm{TiO}_{2}$. The color evolution of glass samples (described in section 3.1) is in agreement with the detected red-shifts of the absorption edge.

The refractive indices were extracted from the optical transmission data in the transparent region using the following equation: $T=2 n /\left(n^{2}+1\right)$. We provide in Table 1 the refractive indices $\mathrm{n}_{1.5}$ at $\lambda=1.5 \mu \mathrm{m}$ (typical wavelength used for optical communication). The $\mathrm{n}_{1.5}$ indices of TT5Wy glasses are plotted in Fig. 8 (b) against $\mathrm{WO}_{3}$ content. In general, the results suggest a practically constant behavior of the refractive index upon adding $\mathrm{TiO}_{2}$ or $\mathrm{WO}_{3}$ with high values ranging between $\sim 2.10$ and $\sim 2.15$. It should be stressed that the above equation slightly underestimates the refractive index value since the multiple reflections of light are neglected and most of the reflection is considered to occur at the two air/glass interfaces (Fresnel reflection). The actual refractive indices will then be provided from the ellipsometric measurements.

We have extracted the optical band gap energy $\mathrm{E}_{\mathrm{g}}$ for all TTxWy glasses from their respective UV absorption edges. Based on the wavelength-dependence of the absorption coefficient $\alpha$ (cf. Fig. 9 (a) for TT5Wy glasses), we plotted $(\alpha h v)^{1 / 2}$ versus the incident photon energy hv (commonly known as Tauc plot) to estimate $\mathrm{E}_{\mathrm{g}}$ (Fig. 9 (b) and Table 1). Decreasing E $_{\mathrm{g}}$ upon adding $\mathrm{WO}_{3}$ in different $\mathrm{TeO}_{2}$-based systems has been previously reported $[59,60]$. In agreement with literature, a slight decrease of $\mathrm{E}_{\mathrm{g}}$ is recorded upon increasing $\mathrm{WO}_{3}$ content from 5 mol.\% (2.88 eV in TT5W5) to $25 \mathrm{~mol} . \%$ (2.74 eV in TT5W25). Upon adding $\mathrm{TiO}_{2}$, 
$\mathrm{E}_{\mathrm{g}}$ tends towards a marginal decrease in $\mathrm{WO}_{3}$-poor compositions (TTxW5) and seems to remain constant in $\mathrm{WO}_{3}$-rich ones (TTxW25).

Moreover, we have extracted the Urbach energy $E_{U}$ values. $E_{U}$ is characteristic of the width of the band-tails at the top of the valence band and the bottom of the conduction band, thus estimating the density of localized states [61]. A highly disordered glass network features a higher density of localized states in the band gap and thus having a high $\mathrm{E}_{\mathrm{U}}$ value. The $\mathrm{E}_{\mathrm{U}}$ value is obtained from the inverse of the slope of the straight line by plotting $\ln (\alpha)$ against $h v$. For TTxWy glasses, the $\mathrm{E}_{\mathrm{U}}$ values are gathered in Table 1 and lie in the range 0.096$0.108 \mathrm{eV} . \mathrm{E}_{\mathrm{U}}$ is found to remain globally stable with increasing $\mathrm{WO}_{3}$ content $(\sim 0.106 \mathrm{eV}$ in TT5Wy glasses). However, a slight decrease is observed upon adding $\mathrm{TiO}_{2}$ at constant $\mathrm{WO}_{3}$ content (for instance from 0.105 to $0.096 \mathrm{eV}$ in TTxW5 glasses). Ghribi et al. [62] recently reported the same behavior in $(100-\mathrm{x}-\mathrm{y}) \mathrm{TeO}_{2}-\mathrm{xTiO}_{2}-\mathrm{yZnO}$ glasses, namely decreasing $\mathrm{E}_{\mathrm{U}}$ from $0.105 \mathrm{eV}$ (at $\mathrm{x}=5$ and $\mathrm{y}=15$ ) to $0.097 \mathrm{eV}$ (at $\mathrm{x}=10$ and $\mathrm{y}=15$ ). It is also worth mentioning that our estimated $\mathrm{E}_{\mathrm{U}}$ values are very close to those reported in literature for $\mathrm{WO}_{3^{-}}$ containing $\mathrm{TeO}_{2}$-based glasses [38]. Therefore, it can be argued that adding $\mathrm{TiO}_{2}$ to the $\mathrm{TeO}_{2}-$ rich network does not induce any significant structural modification of the glass network but instead, considering the compositional dependence of $\mathrm{E}_{\mathrm{U}}$, its incorporation might "lessen" the average structural disorder. In this connection, it is important to recall that upon adding $\mathrm{TiO}_{2}$, we found the glass forming ability to be substantially reduced due to the crystallization of rutile $\mathrm{TiO}_{2}$ in TT20Wy samples.

\subsubsection{Refractive index dispersion by ellipsometry}

From the dispersion curves of TTxWy glasses measured by spectroscopic ellipsometry (Fig. 10 for TT5Wy glasses), we derived the refractive indices $\mathrm{n}_{\infty}(c f$. Table 1) extrapolated to 
infinite wavelength using the following Sellmeier's dispersion formula $[63,64]$ : $\mathrm{n}=\left(\mathrm{A}+\mathrm{B} /\left(1-\mathrm{C} / \lambda^{2}\right)+\mathrm{D} /\left(1-\mathrm{E} / \lambda^{2}\right)\right)^{1 / 2}$ where A-E are fitting constants specific to each sample, allowing to determine $\mathrm{n}_{\infty}=(\mathrm{A}+\mathrm{B}+\mathrm{D})^{1 / 2}$. An excellent fitting quality was achieved as demonstrated by the $\mathrm{R}^{2}$ coefficients ranging between 0.9984 and 0.9999 . The dependence of $\mathrm{n}_{\infty}$ on $\mathrm{TiO}_{2}$ content suggests a steady evolution from an average value of $\sim 2.187$ in TT5Wy to 2.199 in TT15Wy glasses with the highest value $\left(\mathrm{n}_{\infty} \approx 2.206\right)$ recorded from the TT15W15 composition. Adding $\mathrm{WO}_{3}$ results in a steady behavior with an average value of $\sim 2.193$ in TTxW5 and TTxW25. A similar steady evolution of refractive indices is observed in binary $\mathrm{TeO}_{2}-\mathrm{TiO}_{2}$ and $\mathrm{TeO}_{2}-\mathrm{WO}_{3}$ glasses [65] with $\mathrm{n}=2.211-2.226$ from 5 to $15 \mathrm{~mol} . \%$ upon adding $\mathrm{TiO}_{2}$ and $\mathrm{n}=2.211-2.219$ from 10 to 30 mol.\% upon adding $\mathrm{WO}_{3}$ respectively.

From optical transmission and ellipsometric measurements, the refractive index remains practically constant upon adding $\mathrm{TiO}_{2}$ and $\mathrm{WO}_{3}$. This behavior is coherent with the results of the structural analysis (elaborated in section 3.3.) that incorporating $\mathrm{TiO}_{2}$ or $\mathrm{WO}_{3}$ in the $\mathrm{TeO}_{2}$ rich network does not markedly alter the inherent structural features of $\mathrm{Te}-\mathrm{O}-\mathrm{Te}$ bridges. In contrast, when the structural depolymerization takes place (e.g., in presence of $\mathrm{MgO}, \mathrm{ZnO}$, $\mathrm{BaO}[66])$, the refractive index progressively decreases upon adding the network modifiers.

\subsubsection{Bond network nature from the dispersion energy and electronic polarizability}

By applying the single-effective-oscillator model of Wemple and DiDomenico [67] to the refractive index dispersion data, we extracted optical constants that are closely connected with the bond network nature. According to this model, the refractive index dispersion can be interpreted using the following equation: $\frac{1}{n^{2}-1}=\frac{E_{0}}{E_{d}}-\frac{(\mathrm{h} v)^{2}}{E_{0} E_{d}}$. By plotting $1 /\left(\mathrm{n}^{2}-1\right)$ as a function of $(\mathrm{h} v)^{2}$ and fitting a straight line, oscillator parameters $\mathrm{E}_{\mathrm{d}}$ (dispersion energy) and $\mathrm{E}_{0}$ (single oscillator energy) can be determined. In fact, $\mathrm{E}_{\mathrm{d}}$ was found to obey the following empirical 
relationship in more than 100 ionic and covalent crystals [67]: $E_{d}=\beta \cdot N_{c} \cdot Z_{a} \cdot N_{e}$, where $\beta$ parameter approaches $0.37 \pm 0.05 \mathrm{eV}$ and $0.26 \pm 0.04 \mathrm{eV}$ in covalent and ionic crystals respectively, $\mathrm{N}_{\mathrm{c}}$ is the coordination number of the cation, $\mathrm{Z}_{\mathrm{a}}$ the absolute charge number of the anion and $\mathrm{N}_{\mathrm{e}}$ the total number of valence electrons per anion. Since the overall glass network structure (especially that of $\mathrm{TeO}_{2}$-rich network) is only slightly altered upon adding $\mathrm{TiO}_{2}$ or $\mathrm{WO}_{3}$ (section 3.3.), we consider the short-range $\mathrm{N}_{\mathrm{c}}$ parameter in $\mathrm{TTxWy}$ glasses to be slightly increasing upon substituting $\mathrm{TeO}_{2}$ with $\mathrm{TiO}_{2}$ or $\mathrm{WO}_{3}$ since globally, $\mathrm{Te}^{4+}$ cations are four-fold coordinated while $\mathrm{Ti}^{4+}$ and $\mathrm{W}^{6+}$ cations are six-fold coordinated.

$E_{d}$ and $E_{0}$ values lie in the range $26.11-30.37 \mathrm{eV}$ and 6.93-7.99 eV respectively (Table 1). They are found to show an overall decrease with increasing $\mathrm{TiO}_{2}$ and $\mathrm{WO}_{3}$ contents. From the above equation, it is rational to assign this trend to a decreasing $\beta$ parameter. Hence, we suggest that this evolution is associated with an ionic character amplification of the glass network, which can simply be supported by the expected ionicity increase upon substituting Te with $\mathrm{Ti}$ and $\mathrm{W}$ transition metals.

Moreover, we have calculated the electronic polarizability of oxide ions $\alpha_{\mathrm{O} 2}$ - based on optical band gap energies. The used method is based on the Lorentz-Lorenz equation $[68,69]: R_{M}=$ $\left[\left(n^{2}-1\right) /\left(n^{2}+2\right)\right] V_{M}=(4 / 3) \pi N_{A} \alpha_{M}=2.52 \alpha_{M}$, where $R_{M}$ is the molar refraction, $n$ the refractive index, $\mathrm{V}_{\mathrm{M}}$ the molar volume, $\alpha_{\mathrm{M}}$ the molar polarizability and $N_{A}$ the Avogadro's number. This equation allows to calculate $\alpha_{\mathrm{O} 2}$ - in oxide materials by subtracting the cation polarizability (considered as constant) from $\alpha_{\mathrm{M}}$. Following the polarizability approach developed by Dimitrov and Komatsu [70], we calculated for TTxWy glasses the $\alpha_{\mathrm{O} 2}$ - based on $\mathrm{E}_{\mathrm{g}}$ using the following equation: $\alpha_{\mathrm{O} 2-}=\left\{\left(\mathrm{V}_{\mathrm{M}} / 2.52\right)\left[1-\left(\mathrm{E}_{\mathrm{g}}^{1 / 2}-0.98\right) / 1.23\right]-\sum p \alpha_{\mathrm{i}}\right\} \mathrm{q}^{-1}$, where $\mathrm{p}$ and $q$ are the numbers of cations and oxide ions in the chemical formula of the oxide $\mathrm{A}_{\mathrm{p}} \mathrm{O}_{\mathrm{q}}$. The free-cation polarizability $\alpha_{i}$ values of $\mathrm{Te}^{4+}\left(1.595 \AA^{3}\right), \mathrm{Ti}^{4+}\left(0.184 \AA^{3}\right)$ and $\mathrm{W}^{6+}\left(0.147 \AA^{3}\right)$ ions were collected from ref. [70]. The obtained results are listed in Table 1. 


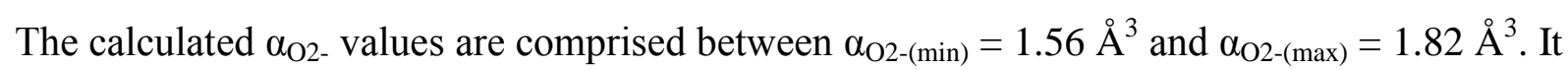
is found that upon adding $\mathrm{WO}_{3}$ from 5 to $25 \mathrm{~mol} \%$, $\alpha_{\mathrm{O} 2}$ - slightly increases from $\sim 1.6$ to $\sim 1.8$ $\AA^{3}$ while remaining practically constant with addition of $\mathrm{TiO}_{2}$. This slight increase of $\alpha_{\mathrm{O} 2}$ values indicates that the overall glass network becomes slightly more "polarized", and thus a little more ionic in nature.

\section{Conclusions.}

A new $\mathrm{TeO}_{2}$-based glass-forming domain has been explored and investigated within the ternary $\mathrm{TeO}_{2}-\mathrm{TiO}_{2}-\mathrm{WO}_{3}$ system. Density, thermal, structural and linear optical properties have been measured and analyzed as a function of $\mathrm{TiO}_{2}$ and $\mathrm{WO}_{3}$ contents.

The structural properties of TTxWy glasses were examined using micro-Raman spectroscopy to highlight the structural roles and effects of adding $\mathrm{TiO}_{2}$ and $\mathrm{WO}_{3}$ on the short- to mediumrange structure. We report the following structural trends:

- Globally, only minor structural modifications are taking place upon adding $\mathrm{TiO}_{2}$ or $\mathrm{WO}_{3}$, (i) indicating that TTxWy glasses collectively share common features of the pure $\mathrm{TeO}_{2}$ glass network and (ii) suggesting the absence of Te-O-Te bond network depolymerization (induced transformation of $\mathrm{TeO}_{4}$ into $\mathrm{TeO}_{3}$ units).

- Upon adding $\mathrm{TiO}_{2}$, we argue that a phase separation occurs between amorphous $\mathrm{TeO}_{2^{-}}$ network and amorphous "rutile-like" $\mathrm{TiO}_{2}$-rich regions (assumed to be of a nanometric size) in binary TTx and ternary TTxWy glasses. Therefore, it seems unlikely that hybrid Te-O-Ti bridges build the bond network in these glasses, thus explaining the limited glass-forming domain to only 15 mol.\%. 
- Upon adding $\mathrm{WO}_{3}$, we argue that (i) only a minor change affects the crosslinked network of Te-O-Te bridges; (ii) at low $\mathrm{WO}_{3}$ contents, uniformly dispersed $\mathrm{WO}_{6}$ octahedra exist in the glass network; and (iii) at higher $\mathrm{WO}_{3}$ contents, amorphous $\mathrm{WO}_{3}$-like regions continuously grow before the crystallization of $\gamma-\mathrm{WO}_{3}$ at $30 \mathrm{~mol} . \%$ of $\mathrm{WO}_{3}$. Let us recall that Sekiya et al. [29] have suggested the same scenario for $\mathrm{TeO}_{2}-\mathrm{WO}_{3}$ glasses

It is important to emphasize that even though these Raman spectroscopy-based findings support the presence of distinct regions as a result of adding $\mathrm{TiO}_{2}$ and $\mathrm{WO}_{3}$, they still do not provide a direct proof of their actual existence. In this regard, we aim in the future to probe the existence of such regions using transmission electron microscopy.

The linear optical properties of TTxWy glasses were measured by the UV-Vis-NIR optical transmission and spectroscopic ellipsometry. In general, the obtained results suggest a steady evolution of the optical properties upon adding $\mathrm{TiO}_{2}$ or $\mathrm{WO}_{3}$ which is consistent with the only minor structural modifications within the TTxWy glasses. The latter possess high refractive index values $\left(\mathrm{n}_{\infty(\min )}=2.173\right.$ and $\left.\mathrm{n}_{\infty(\max )}=2.206\right)$ that remain practically constant upon adding $\mathrm{TiO}_{2}$ or $\mathrm{WO}_{3}$. The evolution of the dispersion energy suggests a slight increase of the network's ionicity upon substituting $\mathrm{TeO}_{2}$ with $\mathrm{TiO}_{2}$ and $\mathrm{WO}_{3}$, which is in agreement with the observed slight increase of the electronic oxide ion polarizability.

As a future work, this evolving bond network nature could be verified by deriving the splitting of the longitudinal optical and transverse optical (LO-TO) modes by means of infrared reflectance spectroscopy. 


\section{Acknowledgements.}

We thank Dr. J. Cornette and Dr. R. Mayet for valued assistance with Raman and XRD experiments respectively. M.R. Zaki gratefully acknowledges the financial support from Conseil Régional du Limousin.

\section{Figure captions.}

Fig. 1. (a) Glass-forming domain obtained within the $(100-x-y) \mathrm{TeO}_{2}-\mathrm{xTiO}_{2}-\mathrm{y} \mathrm{WO}_{3}$ system (labeled TTxWy) surrounded by the yellow frame. Blue and green colored squares and spots correspond to partially crystallized samples in $\mathrm{TiO}_{2}$ and $\mathrm{WO}_{3}$ respectively. (b) Photograph of the obtained glass pellets in their final polished state. The relative positions of pellets are in accord with the black spots in the glass-forming domain.

Fig. 2. DSC curves of TT5Wy glasses. The glass transition and onset crystallization temperatures are given in bold and non-bold typefaces respectively.

Fig. 3. Total-area averaged Raman spectra of TTx glasses $(x=0,2.5,5,10$ and 15) along with the spectrum of $\mathrm{TiTe}_{3} \mathrm{O}_{8}$ (from [22]). The inset is adapted from Fig. 2 in ref. [44] and shows spectra recorded from rutile $\mathrm{TiO}_{2}$ samples with different average crystallite sizes ranging from $5 \mathrm{~nm}$ up to the bulk.

Fig. 4. Evolution of total-area averaged Raman spectra of $\mathrm{TTxWy}$ glasses as a function of $\mathrm{TiO}_{2}$ content. The low-wavenumber (boson peak) and mid- to high-wavenumber regions are supplied apart for more clarity.

Fig. 5. Evolution of total-area averaged Raman spectra of TTxWy glasses as a function of $\mathrm{WO}_{3}$ content. The low-wavenumber (boson peak) and mid- to high-wavenumber regions are supplied apart for more clarity. The Raman spectrum of $\gamma-\mathrm{WO}_{3}$ is reproduced from Fig. 2 in ref. [71].

Fig. 6. Total-area averaged Raman spectra of TT5Wy glasses. The labels A-M correspond to the inserted bands for spectral decomposition. Inset: measured Raman spectrum of pure $\mathrm{TeO}_{2}$ glass featuring the three major broad bands $(\mathrm{E}+\mathrm{F}, \mathrm{G}+\mathrm{H}$ and $\mathrm{I}+\mathrm{J})$.

Fig. 7. Compositional dependence of the normalized intensities of inserted bands for the Raman spectral decomposition of TT5Wy glasses. The areas of bands $\mathrm{E}-\mathrm{H}$ were divided by the $\mathrm{TeO}_{2}$ content; those of bands $\mathrm{D}$ and $\mathrm{K}-\mathrm{M}$ by the $\mathrm{WO}_{3}$ content (see text).

Fig. 8. UV-Vis-NIR light transmission spectra of TTxWy glasses. Insets for TT5Wy: (a) Zoom-in plot of the UV absorption edge; (b) Compositional dependence of the refractive index calculated at $1.5 \mu \mathrm{m}$.

Fig. 9. (a) Evolution of the absorption coefficient as a function of the incident wavelength in TT5Wy. (b) Tauc's plot for the optical band gap energy derived from the absorption coefficient in TT5Wy.

Fig. 10. Refractive index dispersion of TT5Wy glasses. Each dispersion curve corresponds to the average of three measurements from different spots on the same glass pellet. The given refractive index values are obtained by fitting the curves using Sellmeier's equation [63]. Inset: compositional dependence of the refractive index. 


\section{Table captions.}

Table 1. Thermal properties, densities and linear optical properties of TTxWy glasses. * Refractive indices obtained at $\lambda=1.5 \mu \mathrm{m}$ from transmission spectra. $\S$ Refractive indices derived from ellipsometric dispersion curves using Sellmeier's equation.

Table 2. Wavenumbers and vibrational assignments of the inserted bands. Raman bands arising from $\mathrm{TeO}_{2}$ network (Te-O-Te bridges) and their assignments are highlighted in bold typeface. In the spectral decomposition process, the wavenumbers of F, H, L and $\mathrm{M}$ bands were unconstrained and are given herein as wavenumber ranges in TT5Wy glasses.

\section{References.}

[1] S.-H. Kim, T. Yoko, S. Sakka, Linear and nonlinear optical properties of $\mathrm{TeO}_{2}$ glass, J. Am. Ceram. Soc. 76 (1993) 2486-2490. doi:10.1111/j.1151-2916.1993.tb03970.x.

[2] V. Dimitrov, S. Sakka, Linear and nonlinear optical properties of simple oxides. II, J. Appl. Phys. 79 (1996) 1741-1745. doi:10.1063/1.360963.

[3] R.A.H. El-Mallawany, Tellurite glasses handbook: physical properties and data, 2nd ed, Taylor \& Francis, Boca Raton, FL, 2011.

[4] J.C. Champarnaud-Mesjard, S. Blanchandin, P. Thomas, A. Mirgorodsky, T. Merle-Méjean, B. Frit, Crystal structure, Raman spectrum and lattice dynamics of a new metastable form of tellurium dioxide: $\gamma$ $\mathrm{TeO}_{2}$, J. Phys. Chem. Solids. 61 (2000) 1499-1507. doi:10.1016/S0022-3697(00)00012-3.

[5] O. Noguera, T. Merle-Méjean, A.P. Mirgorodsky, M.B. Smirnov, P. Thomas, J.-C. ChamparnaudMesjard, Vibrational and structural properties of glass and crystalline phases of $\mathrm{TeO}_{2}$, J. Non-Cryst. Solids. 330 (2003) 50-60. doi:10.1016/j.jnoncrysol.2003.08.052.

[6] E. Fargin, A. Berthereau, T. Cardinal, G. Le Flem, L. Ducasse, L. Canioni, P. Segonds, L. Sarger, A. Ducasse, Optical non-linearity in oxide glasses, J. Non-Cryst. Solids. 203 (1996) 96-101. doi:10.1016/0022-3093(96)00338-9.

[7] B. Jeansannetas, S. Blanchandin, P. Thomas, P. Marchet, J.C. Champarnaud-Mesjard, T. Merle-Méjean, B. Frit, V. Nazabal, E. Fargin, G. Le Flem, M.O. Martin, B. Bousquet, L. Canioni, S. Le Boiteux, P. Segonds, L. Sarger, Glass structure and optical nonlinearities in thallium(I) tellurium(IV) oxide glasses, J. Solid State Chem. 146 (1999) 329-335. doi:10.1006/jssc.1999.8355.

[8] S. Suehara, P. Thomas, A. Mirgorodsky, T. Merle-Méjean, J.C. Champarnaud-Mesjard, T. Aizawa, S. Hishita, S. Todoroki, T. Konishi, S. Inoue, Non-linear optical properties of $\mathrm{TeO}_{2}$-based glasses: ab initio static finite-field and time-dependent calculations, J. Non-Cryst. Solids. 345-346 (2004) 730-733. doi:10.1016/j.jnoncrysol.2004.08.191.

[9] S. Suehara, P. Thomas, A.P. Mirgorodsky, T. Merle-Méjean, J.C. Champarnaud-Mesjard, T. Aizawa, S. Hishita, S. Todoroki, T. Konishi, S. Inoue, Localized hyperpolarizability approach to the origin of nonlinear optical properties in $\mathrm{TeO}_{2}$-based materials, Phys. Rev. B. 70 (2004). doi:10.1103/PhysRevB.70.205121.

[10] E.M. Roginskii, V.G. Kuznetsov, M.B. Smirnov, O. Noguera, J.-R. Duclère, M. Colas, O. Masson, P. Thomas, Comparative Analysis of the Electronic Structure and Nonlinear Optical Susceptibility of $\alpha-\mathrm{TeO}_{2}$ and $\beta-\mathrm{TeO}_{3}$ Crystals, J. Phys. Chem. C. 121 (2017) 12365-12374. doi:10.1021/acs.jpcc.7b01819.

[11] A.P. Mirgorodsky, M. Soulis, P. Thomas, T. Merle-Méjean, M. Smirnov, Ab initio study of the nonlinear optical susceptibility of $\mathrm{TeO}_{2}$-based glasses, Phys. Rev. B. $73 \quad$ (2006) 134206. doi:10.1103/PhysRevB.73.134206.

[12] M. Soulis, T. Merle-Méjean, A.P. Mirgorodsky, O. Masson, E. Orhan, P. Thomas, M.B. Smirnov, Local molecular orbitals and hyper-susceptibility of $\mathrm{TeO}_{2}$ glass, J. Non-Cryst. Solids. 354 (2008) 199-202. doi:10.1016/j.jnoncrysol.2007.07.036. 
[13] M. Smirnov, A. Mirgorodsky, O. Masson, P. Thomas, Quantum mechanical study of pre-dissociation enhancement of linear and nonlinear polarizabilities of $\left(\mathrm{TeO}_{2}\right)_{n}$ oligomers as a key to understanding the remarkable dielectric properties of $\mathrm{TeO}_{2}$ glasses, J. Phys. Chem. A. 116 (2012) 9361-9369. doi:10.1021/jp303014k.

[14] M.E. Lines, Influence of d orbitals on the nonlinear optical response of transparent transition-metal oxides, Phys. Rev. B. 43 (1991) 11978-11990. doi:10.1103/PhysRevB.43.11978.

[15] S.-H. Kim, T. Yoko, Nonlinear optical properties of $\mathrm{TeO}_{2}$-based glasses: $\mathrm{MO}_{\mathrm{x}}-\mathrm{TeO}(\mathrm{M}=\mathrm{Sc}, \mathrm{Ti}, \mathrm{V}, \mathrm{Nb}$, Mo, Ta, and W) binary glasses, J. Am. Ceram. Soc. 78 (1995) 1061-1065. doi:10.1111/j.11512916.1995.tb08437.x.

[16] T. Sekiya, N. Mochida, A. Ohtsuka, M. Tonokawa, Raman spectra of $\mathrm{MO}_{1 / 2}-\mathrm{TeO}_{2}(\mathrm{M}=\mathrm{Li}, \mathrm{Na}, \mathrm{K}, \mathrm{Rb}, \mathrm{Cs}$ and Tl) glasses, J. Non-Cryst. Solids. 144 (1992) 128-144. doi:10.1016/S0022-3093(05)80393-X.

[17] J.C. McLaughlin, S.L. Tagg, J.W. Zwanziger, The structure of alkali tellurite glasses, J. Phys. Chem. B. 105 (2001) 67-75. doi:10.1021/jp0025779.

[18] N. Berkaïne, J. Cornette, D. Hamani, P. Thomas, O. Masson, A. Mirgorodsky, M. Colas, J. Duclère, T. Merle-Mejéan, J.-C. Champarnaud-Mesjard, M. Smirnov, Structure and dielectric properties of tellurium oxide-based materials, Adv. Electroceramic Mater. II. (2010) 63-74. doi:10.1002/9780470930915.ch7.

[19] G. Upender, C.P. Vardhani, S. Suresh, A.M. Awasthi, V. Chandra Mouli, Structure, physical and thermal properties of $\mathrm{WO}_{3}-\mathrm{GeO}_{2}-\mathrm{TeO}_{2}$ glasses, Mater. Chem. Phys. 121 (2010) 335-341. doi:10.1016/j.matchemphys.2010.01.050.

[20] H. Fares, I. Jlassi, H. Elhouichet, M. Férid, Investigations of thermal, structural and optical properties of tellurite glass with $\mathrm{WO}_{3}$ adding, J. Non-Cryst. Solids. 396-397 (2014) 1-7. doi:10.1016/j.jnoncrysol.2014.04.012.

[21] J.C. Sabadel, P. Armand, D. Cachau-Herreillat, P. Baldeck, O. Doclot, A. Ibanez, E. Philippot, Structural and nonlinear optical characterizations of tellurium oxide-based glasses: $\mathrm{TeO}_{2}-\mathrm{BaO}-\mathrm{TiO}_{2}$, J. Solid State Chem. 132 (1997) 411-419. doi:10.1006/jssc.1997.7499.

[22] M. Soulis, A.P. Mirgorodsky, T. Merle-Méjean, O. Masson, P. Thomas, M. Udovic, The role of modifier's cation valence in structural properties of $\mathrm{TeO}_{2}$-based glasses, J. Non-Cryst. Solids. 354 (2008) 143-149. doi:10.1016/j.jnoncrysol.2007.07.032.

[23] M. Udovic, P. Thomas, A. Mirgorodsky, O. Masson, T. Merle-Mejean, C. Lasbrugnas, J.C. ChamparnaudMesjard, T. Hayakawa, Formation domain and characterization of new glasses within the $\mathrm{Tl}_{2} \mathrm{O}-\mathrm{TiO}_{2}-$ $\mathrm{TeO}_{2}$ system, Mater. Res. Bull. 44 (2009) 248-253. doi:10.1016/j.materresbull.2008.10.001.

[24] M. Udovic, P. Thomas, A. Mirgorodsky, O. Durand, M. Soulis, O. Masson, T. Merle-Méjean, J.C. Champarnaud-Mesjard, Thermal characteristics, Raman spectra and structural properties of new tellurite glasses within the $\mathrm{Bi}_{2} \mathrm{O}_{3}-\mathrm{TiO}_{2}-\mathrm{TeO}_{2}$ system, J. Solid State Chem. 179 (2006) 3252-3259. doi:10.1016/j.jssc.2006.06.016.

[25] N. Ghribi, M. Dutreilh-Colas, J.-R. Duclère, T. Hayakawa, J. Carreaud, R. Karray, A. Kabadou, P. Thomas, Thermal, optical and structural properties of glasses within the $\mathrm{TeO}_{2}-\mathrm{TiO}_{2}-\mathrm{ZnO}$ system, J. Alloys Compd. 622 (2015) 333-340. doi:10.1016/j.jallcom.2014.10.063.

[26] G. Meunier, J. Galy, Sur une déformation inédite du reseau de type fluorine. Structure cristalline des phases $\mathrm{MTe}_{3} \mathrm{O}_{8}(\mathrm{M}=\mathrm{Ti}, \mathrm{Sn}, \mathrm{Hf}, \mathrm{Zr})$, Acta Crystallogr. B. 27 (1971) 602-608. doi:10.1107/S0567740871002620.

[27] S. Blanchandin, P. Marchet, P. Thomas, J.C. Champarnaud-Mesjard, B. Frit, A. Chagraoui, New investigations within the $\mathrm{TeO}_{2}-\mathrm{WO}_{3}$ system: phase equilibrium diagram and glass crystallization, J. Mater. Sci. 34 (1999) 4285-4292. doi:10.1023/A:1004667223028.

[28] V. Dimitrov, M. Arnaudov, Y. Dimitriev, IR-spectral study of the effect of $\mathrm{WO}_{3}$ on the structure of tellurite glasses, Monatshefte Für Chem. Chem. Mon. 115 (1984) 987-991. doi:10.1007/BF00798766.

[29] T. Sekiya, N. Mochida, S. Ogawa, Structural study of $\mathrm{WO}_{3}-\mathrm{TeO}_{2}$ glasses, J. Non-Cryst. Solids. 176 (1994) 105-115. doi:10.1016/0022-3093(94)90067-1.

[30] I. Shaltout, Y. Tang, R. Braunstein, A.M. Abu-Elazm, Structural studies of tungstate-tellurite glasses by Raman spectroscopy and differential scanning calorimetry, J. Phys. Chem. Solids. 56 (1995) 141-150. doi:10.1016/0022-3697(94)00150-2.

[31] B.V.R. Chowdari, P.P. Kumari, Studies on $\mathrm{Ag}_{2} \mathrm{O}-\mathrm{M}_{\mathrm{x}} \mathrm{O}_{\mathrm{y}}-\mathrm{TeO}_{2}\left(\mathrm{M}_{\mathrm{x}} \mathrm{O}_{\mathrm{y}}=\mathrm{WO}_{3}, \mathrm{MoO}_{3}, \mathrm{P}_{2} \mathrm{O}_{5}\right.$ and $\left.\mathrm{B}_{2} \mathrm{O}_{3}\right)$ ionic conducting glasses, in: Solid State Ion., Elsevier, 1998: pp. 665-675. doi:10.1016/S0167-2738(98)003932.

[32] V.O. Sokolov, V.G. Plotnichenko, E.M. Dianov, Structure of $\mathrm{WO}_{3}-\mathrm{TeO}_{2}$ glasses, Inorg. Mater. 43 (2007) 194-213. doi:10.1134/S0020168507020173.

[33] G. Upender, S. Bharadwaj, A.M. Awasthi, V. Chandra Mouli, Glass transition temperature-structural studies of tungstate tellurite glasses, Mater. Chem. Phys. 118 (2009) 298-302. doi:10.1016/j.matchemphys.2009.07.058. 
[34] A. Mirgorodsky, M. Colas, M. Smirnov, T. Merle-Méjean, R. El-Mallawany, P. Thomas, Structural peculiarities and Raman spectra of $\mathrm{TeO}_{2}-\mathrm{WO}_{3}$-based glasses: A fresh look at the problem, J. Solid State Chem. 190 (2012) 45-51. doi:10.1016/j.jssc.2012.02.011.

[35] A. Kaur, A. Khanna, V.G. Sathe, F. Gonzalez, B. Ortiz, Optical, thermal, and structural properties of $\mathrm{Nb}_{2} \mathrm{O}_{5}-\mathrm{TeO}_{2}$ and $\mathrm{WO}_{3}-\mathrm{TeO}_{2}$ glasses, Phase Transit. $86 \quad$ (2013) 598-619. doi:10.1080/01411594.2012.727998.

[36] B.O. Loopstra, P. Boldrini, Neutron diffraction investigation of $\mathrm{WO}_{3}$, Acta Crystallogr. 21 (1966) 158162. doi:10.1107/S0365110X66002469.

[37] V.V. Safonov, Interactions in the $\mathrm{TeO}_{2}-\mathrm{TiO}_{2}-\mathrm{WO}_{3}$ system, Russ. J. Inorg. Chem. 53 (2008) $460-461$. doi:10.1134/S0036023608030224.

[38] D.M. Munoz-Martín, $\mathrm{TeO}_{2}$-based film glasses for photonic applications: structural and optical properties., PhD, Universidad Complutense de Madrid, 2010.

[39] D. De Sousa Meneses, Software utility for the creation of optical function (FOCUS), CEMHTI UPR 3079 CNRS Orléans, France, 2004. http://www.cemhti.cnrs-orleans.fr/pot/software/focus.html.

[40] S. Tanisaki, Crystal structure of monoclinic tungsten trioxide at room temperature, J. Phys. Soc. Jpn. 15 (1960) 573-581. doi:10.1143/JPSJ.15.573.

[41] A. H. Dietzel, Die kationenfeldstärken und ihre beziehungen zu entglasungsvorgängen, zur verbindungsbildung und zu den schmelzpunkten von silikaten, Z Electrochem. 48 (1942) 9-23.

[42] A.K. Varshneya, Chapter 3 - Glass formation principles, in: Fundam. Inorg. Glas., Academic Press, San Diego, 1994: pp. 27-59.

[43] R.D. Shannon, Revised effective ionic radii and systematic studies of interatomic distances in halides and chalcogenides, Acta Crystallogr. Sect. A. 32 (1976) 751-767. doi:10.1107/S0567739476001551.

[44] V. Swamy, B.C. Muddle, Q. Dai, Size-dependent modifications of the Raman spectrum of rutile $\mathrm{TiO}_{2}$, Appl. Phys. Lett. 89 (2006) 163118. doi:10.1063/1.2364123.

[45] S. Zhou, E. Čižmár, K. Potzger, M. Krause, G. Talut, M. Helm, J. Fassbender, S.A. Zvyagin, J. Wosnitza, H. Schmidt, Origin of magnetic moments in defective $\mathrm{TiO}_{2}$ single crystals, Phys. Rev. B. 79 (2009). doi:10.1103/PhysRevB.79.113201.

[46] I. Lukačević, S.K. Gupta, P.K. Jha, D. Kirin, Lattice dynamics and Raman spectrum of rutile $\mathrm{TiO}_{2}$ : The role of soft phonon modes in pressure induced phase transition, Mater. Chem. Phys. 137 (2012) 282-289. doi:10.1016/j.matchemphys.2012.09.022.

[47] O. Noguera, T. Merle-Méjean, A.P. Mirgorodsky, P. Thomas, J.-C. Champarnaud-Mesjard, Dynamics and crystal chemistry of tellurites. II. Composition- and temperature-dependence of the Raman spectra of $\mathrm{x}\left(\mathrm{Tl}_{2} \mathrm{O}\right)+(1-\mathrm{x}) \mathrm{TeO}_{2}$ glasses: evidence for a phase separation?, J. Phys. Chem. Solids. 65 (2004) 981-993. doi:10.1016/j.jpcs.2003.11.020.

[48] S.S. Sukhov, V.N. Sigaev, P. Perniche, A. Aronne, E. Fanelli, S. Brovelli, A. Paleari, G.E. Malashkevich, Structure and properties of erbium-titanium-tellurite glass, Glass Ceram. 63 (2006) 399-402. doi:10.1007/s10717-006-0133-6.

[49] N. Gupta, A. Khanna, F. Gonzàlez, R. Iordanova, Thermal characteristics, Raman spectra, optical and structural properties of $\mathrm{TiO}_{2}-\mathrm{Bi}_{2} \mathrm{O}_{3}-\mathrm{B}_{2} \mathrm{O}_{3}-\mathrm{TeO}_{2}$ glasses, in: 2017: p. 070005. doi:10.1063/1.4980440.

[50] O. Noguera, Propriétés structurales, vibrationnelles et diélectriques de matériaux à base d'oxyde de tellure, $\mathrm{PhD}$ thesis, Université de Limoges, 2003.

[51] A.P. Mirgorodsky, T. Merle-Méjean, J.-C. Champarnaud, P. Thomas, B. Frit, Dynamics and structure of $\mathrm{TeO}_{2}$ polymorphs: model treatment of paratellurite and tellurite; Raman scattering evidence for new $\gamma$ - and $\delta$-phases, J. Phys. Chem. Solids. 61 (2000) 501-509. doi:10.1016/S0022-3697(99)00263-2.

[52] T. Vasileiadis, S.N. Yannopoulos, Photo-induced oxidation and amorphization of trigonal tellurium: A means to engineer hybrid nanostructures and explore glass structure under spatial confinement, J. Appl. Phys. 116 (2014) 103510. doi:10.1063/1.4894868.

[53] Y.V. Denisov, A.A. Zubovich, Boson Peak and Medium-Range Order Structure of Alkali Borate Glasses, Glass Phys. Chem. 29 (2003) 345-352. doi:10.1023/A:1025112607893.

[54] E. Stavrou, C. Tsiantos, R.D. Tsopouridou, S. Kripotou, A.G. Kontos, C. Raptis, B. Capoen, M. Bouazaoui, S. Turrell, S. Khatir, Raman scattering boson peak and differential scanning calorimetry studies of the glass transition in tellurium-zinc oxide glasses, J. Phys. Condens. Matter. 22 (2010) 195103. doi:10.1088/0953-8984/22/19/195103.

[55] P. Charton, L. Gengembre, P. Armand, $\mathrm{TeO}_{2}-\mathrm{WO}_{3}$ glasses: Infrared, XPS and XANES structural characterizations, J. Solid State Chem. 168 (2002) 175-183. doi:10.1006/jssc.2002.9707.

[56] A.P. Sokolov, A. Kisliuk, M. Soltwisch, D. Quitmann, Medium-range order in glasses: Comparison of Raman and diffraction measurements, Phys. Rev. Lett. 69 (1992) 1540-1543. doi:10.1103/PhysRevLett.69.1540. 
[57] A.G. Kalampounias, G.N. Papatheodorou, S.N. Yannopoulos, A temperature dependence Raman study of the $0.1 \quad \mathrm{Nb}_{2} \mathrm{O}_{5}-0.9 \quad \mathrm{TeO}_{2}$ glass-forming system, J. Phys. Chem. Solids. 67 (2006) 725-731. doi:10.1016/j.jpcs.2005.11.001.

[58] A.M. Efimov, V.G. Pogareva, A.V. Shashkin, Water-related bands in the IR absorption spectra of silicate glasses, J. Non-Cryst. Solids. 332 (2003) 93-114. doi:10.1016/j.jnoncrysol.2003.09.020.

[59] E.S. Yousef, A. El-Adawy, N. El Koshkhany, E.R. Shaaban, Optical and acoustic properties of $\mathrm{TeO}_{2}-\mathrm{WO}_{3}$ glasses with small amount of additive $\mathrm{ZrO}_{2}$, J. Phys. Chem. Solids. 67 (2006) 1649-1655. doi:10.1016/j.jpcs.2006.02.014.

[60] M.M. Umair, A.K. Yahya, M.K. Halimah, H.A.A. Sidek, Effects of increasing tungsten on structural, elastic and optical properties of $\mathrm{xWO}_{3}-(40-\mathrm{x}) \mathrm{Ag}_{2} \mathrm{O}-60 \mathrm{TeO}_{2}$ Glass System, J. Mater. Sci. Technol. 31 (2015) 83-90. doi:10.1016/j.jmst.2014.10.002.

[61] F. Urbach, The long-wavelength edge of photographic sensitivity and of the electronic absorption of solids, Phys. Rev. 92 (1953) 1324-1324. doi:10.1103/PhysRev.92.1324.

[62] N. Ghribi, Synthèse, caractérisations structurale et élastique de nouveaux matériaux tellurites pour des applications en optique non linéaire, PhD thesis, Université de Limoges, 2015.

[63] Sellmeier, Zur Erklärung der abnormen Farbenfolge im Spectrum einiger Substanzen, Ann. Phys. Chem. 219 (1871) 272-282. doi:10.1002/andp.18712190612.

[64] G. Ghosh, Sellmeier coefficients and dispersion of thermo-optic coefficients for some optical glasses, Appl. Opt. 36 (1997) 1540. doi:10.1364/AO.36.001540.

[65] G. Dai, F. Tassone, A. LiBassi, V. Russo, C.E. Bottani, F. D’Amore, $\mathrm{TeO}_{2}$-based glasses containing $\mathrm{Nb}_{2} \mathrm{O}_{5}, \mathrm{TiO}_{2}$, and $\mathrm{WO}_{3}$ for discrete Raman fiber amplification, IEEE Photonics Technol. Lett. 16 (2004) 1011-1013. doi:10.1109/LPT.2004.824963.

[66] S. Manning, H. Ebendorff-Heidepriem, T.M. Monro, Ternary tellurite glasses for the fabrication of nonlinear optical fibres, Opt. Mater. Express. 2 (2012) 140-152. doi:10.1364/OME.2.000140.

[67] S.H. Wemple, Refractive-index behavior of amorphous semiconductors and glasses, Phys. Rev. B. 7 (1973) 3767-3777. doi:10.1103/PhysRevB.7.3767.

[68] H.A. Lorentz, Ueber die Beziehung zwischen der Fortpflanzungsgeschwindigkeit des Lichtes und der Körperdichte, Ann. Phys. Chem. 245 (1880) 641-665. doi:10.1002/andp.18802450406.

[69] L. Lorenz, Über die Refractionsconstante, Wiedem. Ann. 11 (1880) 70.

[70] V. Dimitrov, T. Komatsu, An interpretation of optical properties of oxides and oxide glasses in terms of the electronic ion polarizability and average single bond strength, Journal of the University of Chemical Technology and Metallurgy. 45 (2010) 219-250.

[71] M.F. Daniel, B. Desbat, J.C. Lassegues, B. Gerand, M. Figlarz, Infrared and Raman study of $\mathrm{WO}_{3}$ tungsten trioxides and $\mathrm{WO}_{3}, \mathrm{xH}_{2} \mathrm{O}$ tungsten trioxide hydrates, J. Solid State Chem. 67 (1987) 235-247. doi:10.1016/0022-4596(87)90359-8. 


\begin{tabular}{|c|c|c|c|c|c|c|c|c|c|c|}
\hline Sam & $\begin{array}{c}\mathbf{T}_{\mathbf{g}} \\
\left({ }^{\circ} \mathrm{C}\right) \\
\pm 1 \\
\end{array}$ & $\begin{array}{c}\Delta \mathbf{T} \\
\left({ }^{\circ} \mathrm{C}\right) \\
\pm 1 \\
\end{array}$ & $\begin{array}{l}\text { Density } \\
\left(\mathrm{g} / \mathrm{cm}^{3}\right)\end{array}$ & $\begin{array}{c}\mathbf{E}_{\mathbf{g}} \\
(\mathrm{eV}) \\
\pm 0.020 \\
\end{array}$ & $\begin{array}{c}\mathbf{E}_{\mathbf{U}} \\
(\mathrm{eV}) \\
\pm 0.002 \\
\end{array}$ & $\begin{array}{c}\mathbf{n}_{1.5}{ }^{*} \\
\pm 0.010\end{array}$ & $\mathbf{n}_{\infty} \S$ & $\begin{array}{c}\mathbf{E}_{\mathbf{0}} \\
(\mathrm{eV})\end{array}$ & $\begin{array}{c}\mathbf{E}_{\mathbf{d}} \\
(\mathrm{eV})\end{array}$ & $\begin{array}{l}\alpha_{\mathrm{O} 2-} \\
\left(\AA^{3}\right)\end{array}$ \\
\hline TT5 & 328 & 31 & & 2.880 & 0.105 & 2.132 & & & & \pm 0.048 \\
\hline TT5 & 341 & 36 & & 2.842 & 0.105 & 2.127 & & & & $\begin{array}{c}1.653 \\
\pm 0.053\end{array}$ \\
\hline TT5 & 355 & 38 & & 2.789 & 0.106 & 2.122 & & & & \\
\hline TT5W20 & 365 & 38 & & 2.764 & 0.105 & 2.141 & & & & \\
\hline TT5 & 376 & 41 & & 2.744 & 0.107 & 2.118 & & & & \\
\hline $\mathrm{T}$ & 353 & 45 & $\begin{array}{c}5.5 \\
\pm 0 .\end{array}$ & 2.843 & 0.100 & 2.11 & & & & $\begin{array}{c}1.564 \\
\pm 0.047\end{array}$ \\
\hline$T$ & 364 & 45 & $\begin{array}{r}5.6 \\
\pm 0 .( \\
\end{array}$ & 2.812 & 0.103 & 2.123 & $\begin{array}{c}2.197 \\
\pm 0.014\end{array}$ & & & $\begin{array}{c}1.682 \\
\pm 0.060\end{array}$ \\
\hline TT1 & 376 & 52 & $\begin{array}{r}5.7 \\
\pm 0 .(\end{array}$ & 2.776 & 0.103 & 2.128 & $\begin{array}{c}2.182 \\
\pm 0.024\end{array}$ & $\begin{array}{l}7 \\
89\end{array}$ & & $\begin{array}{c}1.731 \\
\pm 0.055\end{array}$ \\
\hline TT10 & 389 & 54 & $\begin{array}{r}5.7 \\
\pm 0 .\end{array}$ & 2.758 & 0.103 & 2.133 & $\begin{array}{c}2.191 \\
\pm 0.013 \\
\end{array}$ & $\begin{array}{r}7 . \\
\pm 0 \\
\end{array}$ & & $\begin{array}{c}1.777 \\
\pm 0.066 \\
\end{array}$ \\
\hline TT10 & 399 & 57 & & 2.736 & 108 & 2.134 & $\begin{array}{c}2.190 \\
\pm 0.018 \\
\end{array}$ & & & $\begin{array}{c}1.823 \\
\pm 0.046 \\
\end{array}$ \\
\hline TT15 & 380 & 38 & & 2.826 & 0.096 & 2.120 & $\begin{array}{c}2.198 \\
\pm 0.024\end{array}$ & & & $\begin{array}{c}1.669 \\
\pm 0.045\end{array}$ \\
\hline TT & 391 & 39 & $\begin{array}{c}5.535 \\
\pm 0.004 \\
\end{array}$ & 2.800 & 0.102 & & $\begin{array}{c}2.198 \\
\pm 0.012 \\
\end{array}$ & $\begin{array}{c}7.025 \\
\pm 0.115 \\
\end{array}$ & $\begin{array}{r}26.659 \\
\pm 1.169 \\
\end{array}$ & $\begin{array}{c}1.717 \\
\pm 0.040 \\
\end{array}$ \\
\hline TT1 & 405 & 40 & $\begin{array}{c}5.623 \\
\pm 0.008\end{array}$ & 2.782 & 0 & 2 & $\begin{array}{c}2.206 \\
\pm 0.015\end{array}$ & $\begin{array}{c}7.048 \\
\pm 0.081\end{array}$ & & $\begin{array}{c}1.750 \\
\pm 0.046\end{array}$ \\
\hline TT15W20 & 414 & 52 & $\begin{array}{c}5.682 \\
\pm 0.007\end{array}$ & 2 & 0 & 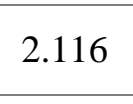 & $\begin{array}{c}2.196 \\
\pm 0.023\end{array}$ & $\begin{array}{c}7.143 \\
\pm 0.162\end{array}$ & $\begin{array}{l}27.132 \\
\pm 2.321 \\
\end{array}$ & $\begin{array}{c}1.797 \\
\pm 0.035\end{array}$ \\
\hline (1) & 426 & 48 & $\begin{array}{c}5.757 \\
\pm 0.005 \\
\end{array}$ & 2.150 & 0.100 & - & $\begin{array}{c}2.199 \\
\pm 0.011 \\
\end{array}$ & $\begin{array}{c}6.987 \\
\pm 0.080\end{array}$ & $\begin{array}{r}26.604 \\
\pm 0.809 \\
\end{array}$ & $\begin{array}{c}1.813 \\
\pm 0.032 \\
\end{array}$ \\
\hline
\end{tabular}




\begin{tabular}{|c|c|c|}
\hline Band & $\begin{array}{l}\text { Wavenumber } \\
\left(\mathrm{cm}^{-1}\right)\end{array}$ & Raman bands assignments \\
\hline A & $44.0-45.6$ & - The boson peak, ascribed to an excess density of vibrational states [56]. \\
\hline B & 146.9 (fixed) & $\begin{array}{l}\text { - Intra-chain vibrations of Te-Te bonds (as in amorphous metallic trigonal } \\
\mathrm{Te} \text { ) [52]. }\end{array}$ \\
\hline $\mathrm{C}$ & 230 (fixed) & - Bending vibrations of $\mathrm{WO}_{6}$ octahedra (as in $\gamma-\mathrm{WO}_{3}$ ) [71]. \\
\hline $\mathrm{D}$ & 351 (fixed) & - Bending vibrations of distorted $\mathrm{WO}_{6}$ octahedra [71]. \\
\hline $\mathbf{E}$ & 425 (fixed) & $\begin{array}{l}\text { - Symmetric stretching vibrations in nearly symmetric Te-O-Te } \\
\text { bridges }\left(\text { as in } \gamma \text { - } \mathrm{TeO}_{2} \text { ) }[4,51] \text {. }\right. \\
\text { - Motions of oxide ions in } \mathrm{O}-\mathrm{Ti}-\mathrm{O} \text { bridges along the } c \text { axis }\left(\mathrm{E}_{\mathrm{g}} \text { mode of }\right. \\
\left.\text { rutile } \mathrm{TiO}_{2}\right)[46] \text {. }\end{array}$ \\
\hline $\mathbf{F}$ & $501.8-505.8$ & - Symmetric stretching vibrations in Te-O-Te bridges [4,51]. \\
\hline $\mathbf{G}$ & 607 (fixed) & $\begin{array}{l}\text { - Asymmetric stretching vibrations in nearly symmetric } \mathbf{T e - O}-\mathbf{T e} \\
\left.\text { bridges (as in } \gamma-\mathrm{TeO}_{2}\right)[4,51] \text {. } \\
\text { - Motions of oxide ions in } \mathrm{O}-\mathrm{Ti}-\mathrm{O} \text { bridges perpendicular to the } c \text { axis }\left(\mathrm{A}_{1 \mathrm{~g}}\right. \\
\left.\text { mode of rutile } \mathrm{TiO}_{2}\right)[46] \text {. }\end{array}$ \\
\hline $\mathbf{H}$ & $657.9-660.4$ & $\begin{array}{l}\text { - Asymmetric stretching vibrations in asymmetric Te-O-Te bridges } \\
{[4,51] \text {. }}\end{array}$ \\
\hline $\mathbf{I}$ & 715 (fixed) & $\begin{array}{l}\text { - Asymmetric stretching vibrations in asymmetric Te-O-Te bridges } \\
\text { [4,51]. } \\
\text { - Symmetric stretching vibrations in } \mathrm{W}-\mathrm{O}-\mathrm{W} \text { bridges (as in } \gamma-\mathrm{WO}_{3} \text { ) [71]. }\end{array}$ \\
\hline $\mathbf{J}$ & 772 (fixed) & - Asymmetric stretching of essentially covalent $\mathrm{Te}-{ }_{e q} \mathrm{O}$ bonds $[4,51]$. \\
\hline $\mathrm{K}$ & 820 (fixed) & - Asymmetric stretching vibrations in $\mathrm{W}-\mathrm{O}-\mathrm{W}$ bridges (as in $\gamma-\mathrm{WO}_{3}$ ) [71]. \\
\hline $\mathrm{L}$ & $852.3-863.1$ & $\begin{array}{l}\text { - Stretching vibrations of } \mathrm{W}-\mathrm{O} \text { bonds in } \mathrm{W}-\mathrm{O}-\mathrm{W} \text { bridges [29]. } \\
\text { - Antisymmetric stretching vibrations of } \mathrm{Ti}-\mathrm{O} \text { bonds }\left(\mathrm{B}_{2 \mathrm{~g}} \text { mode of rutile }\right. \\
\left.\mathrm{TiO}_{2}\right)[44,45] \text {. }\end{array}$ \\
\hline M & $925-934$ & - Asymmetric stretching vibrations of $\mathrm{W}-\mathrm{O}$ bonds [71]. \\
\hline
\end{tabular}


(a)

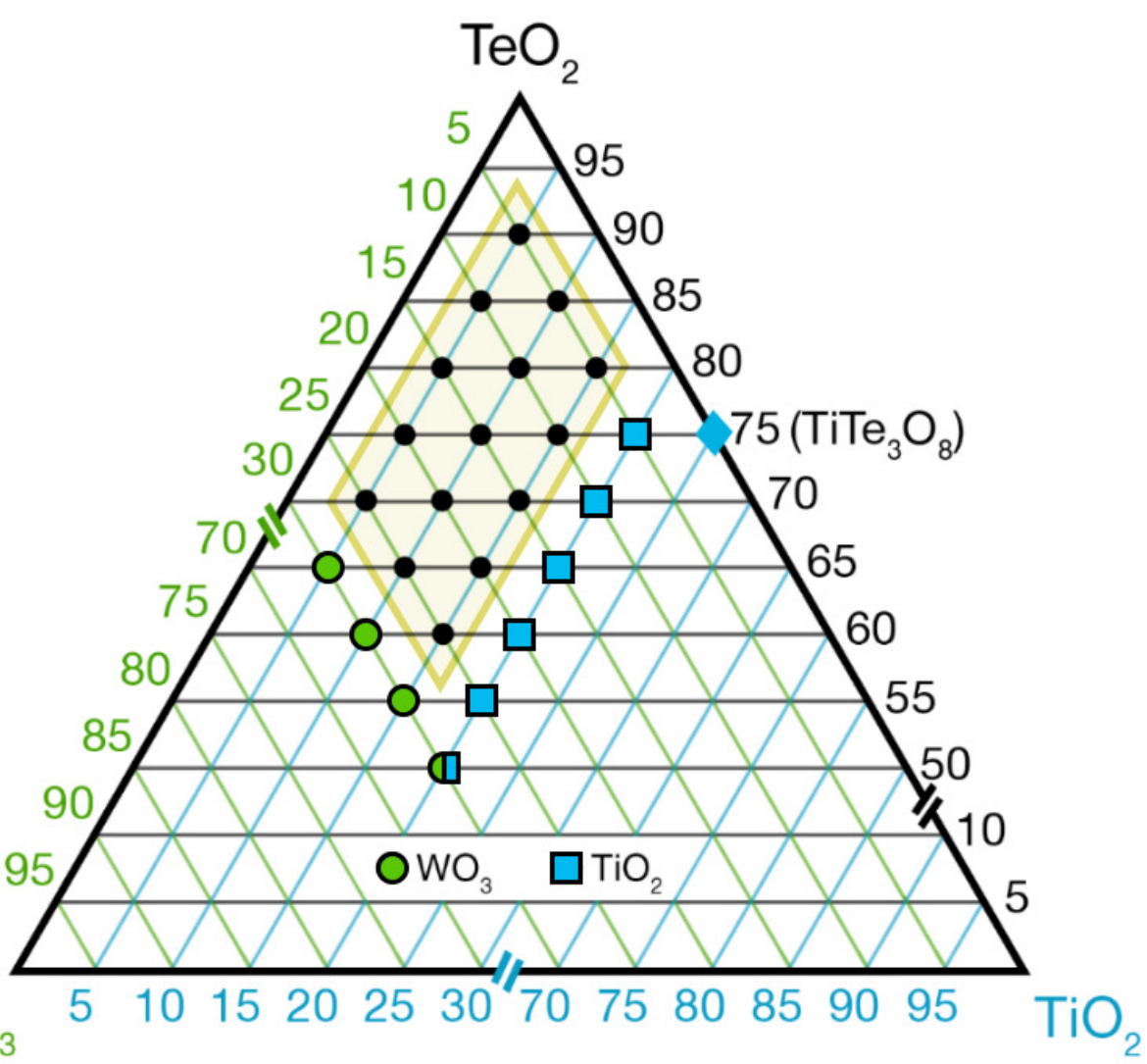

(b)

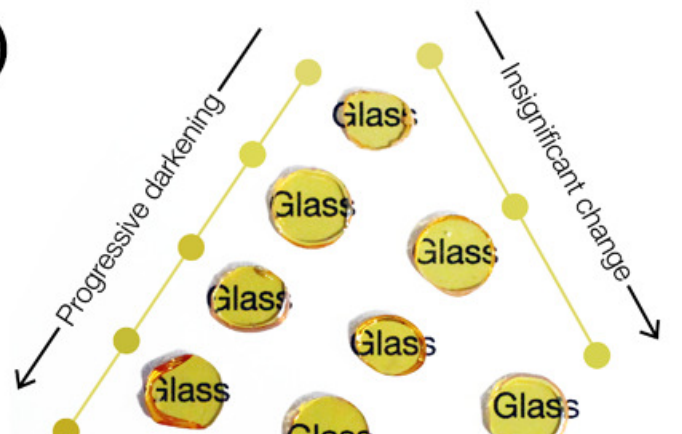

(ilas) Glass Glass

(alas. Glas:

$1 \mathrm{~cm}$

(ilas): 


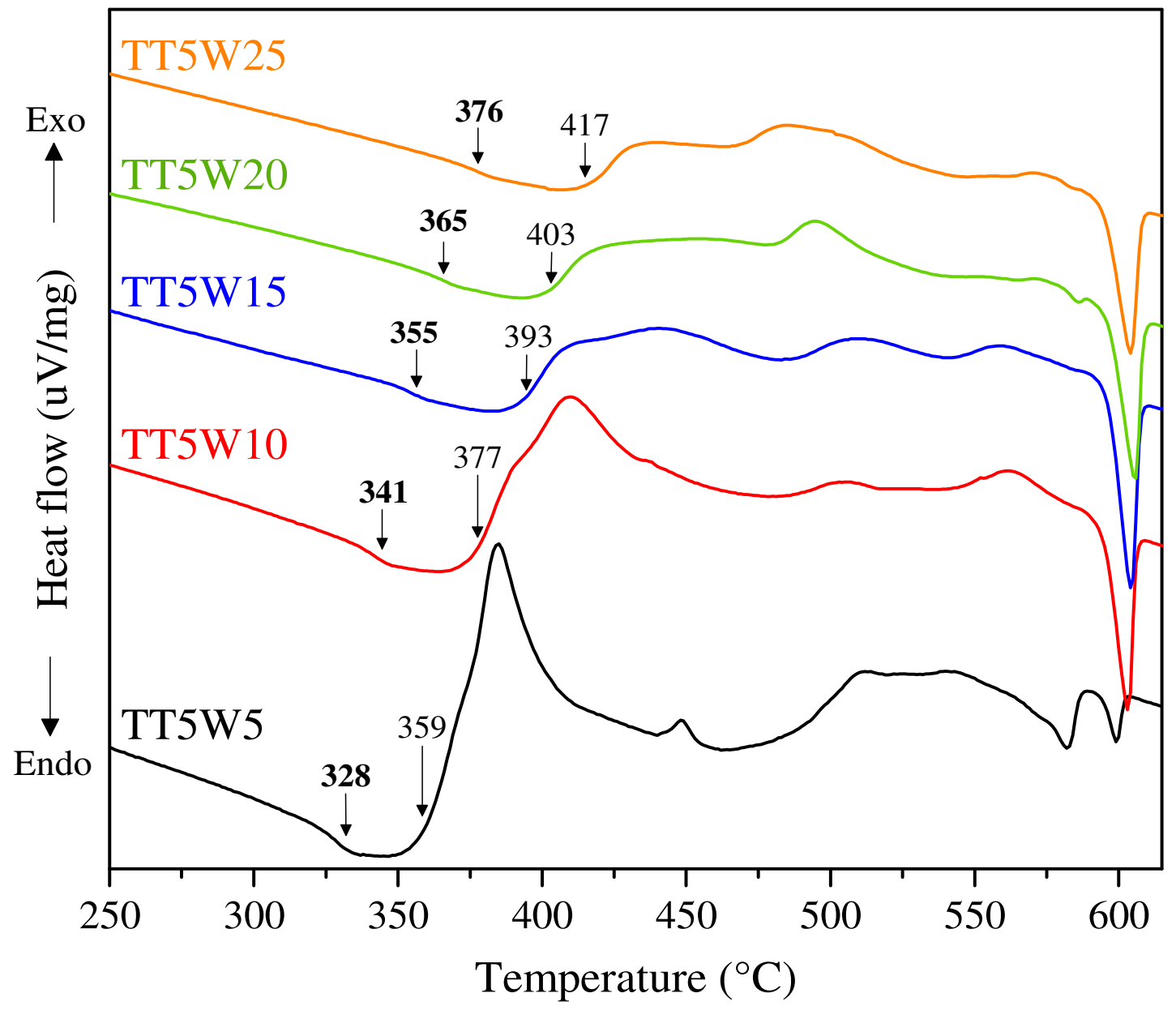




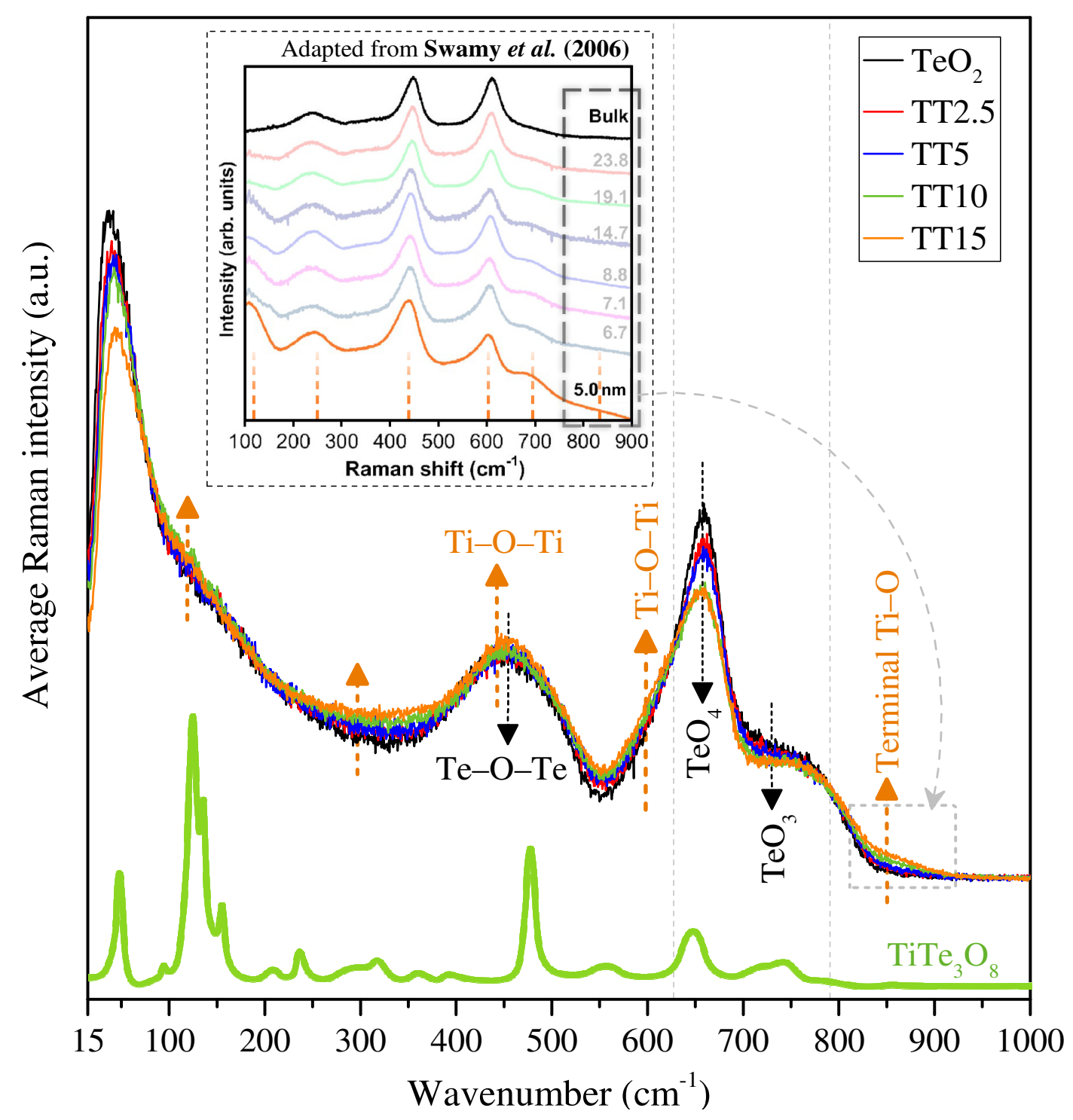




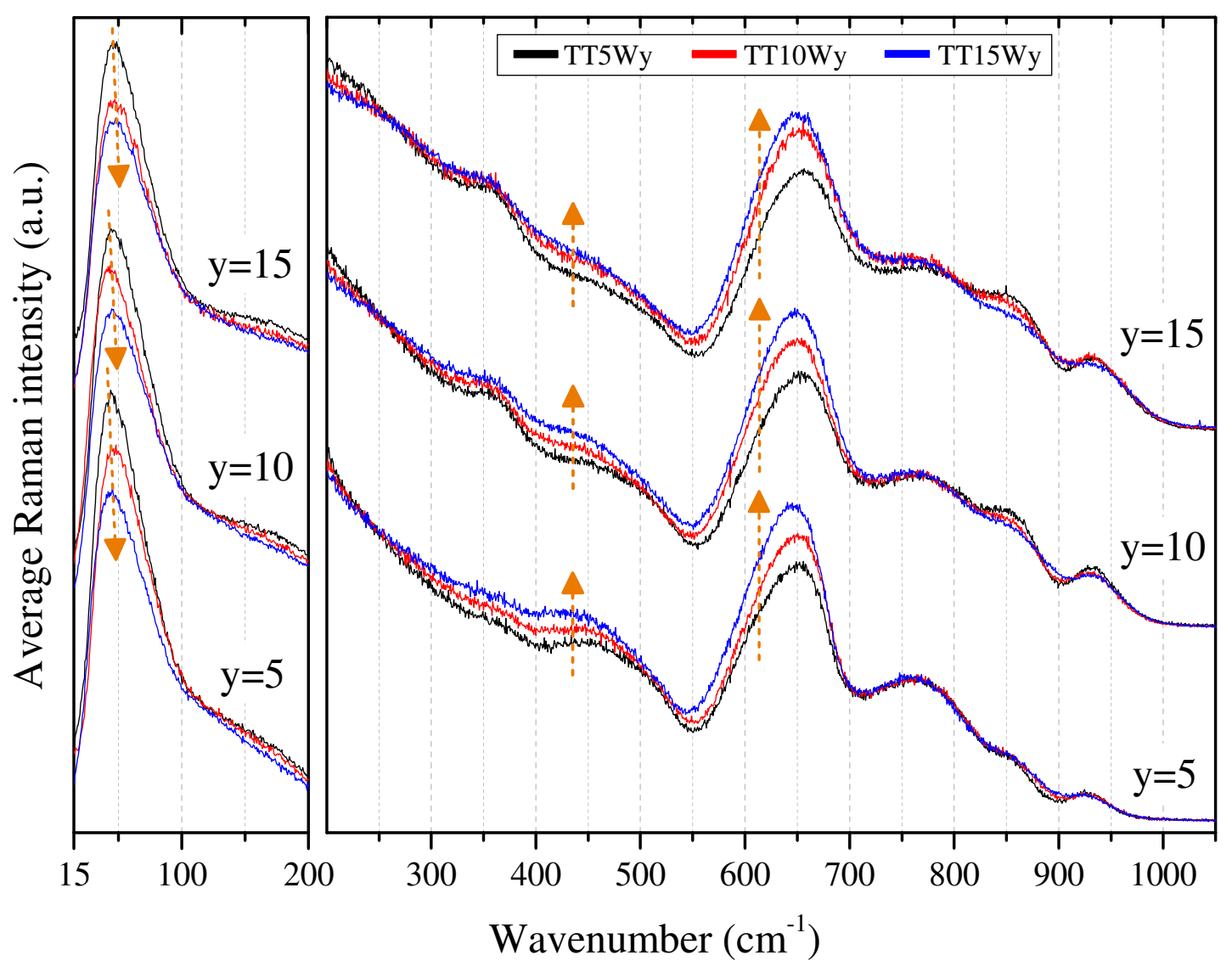




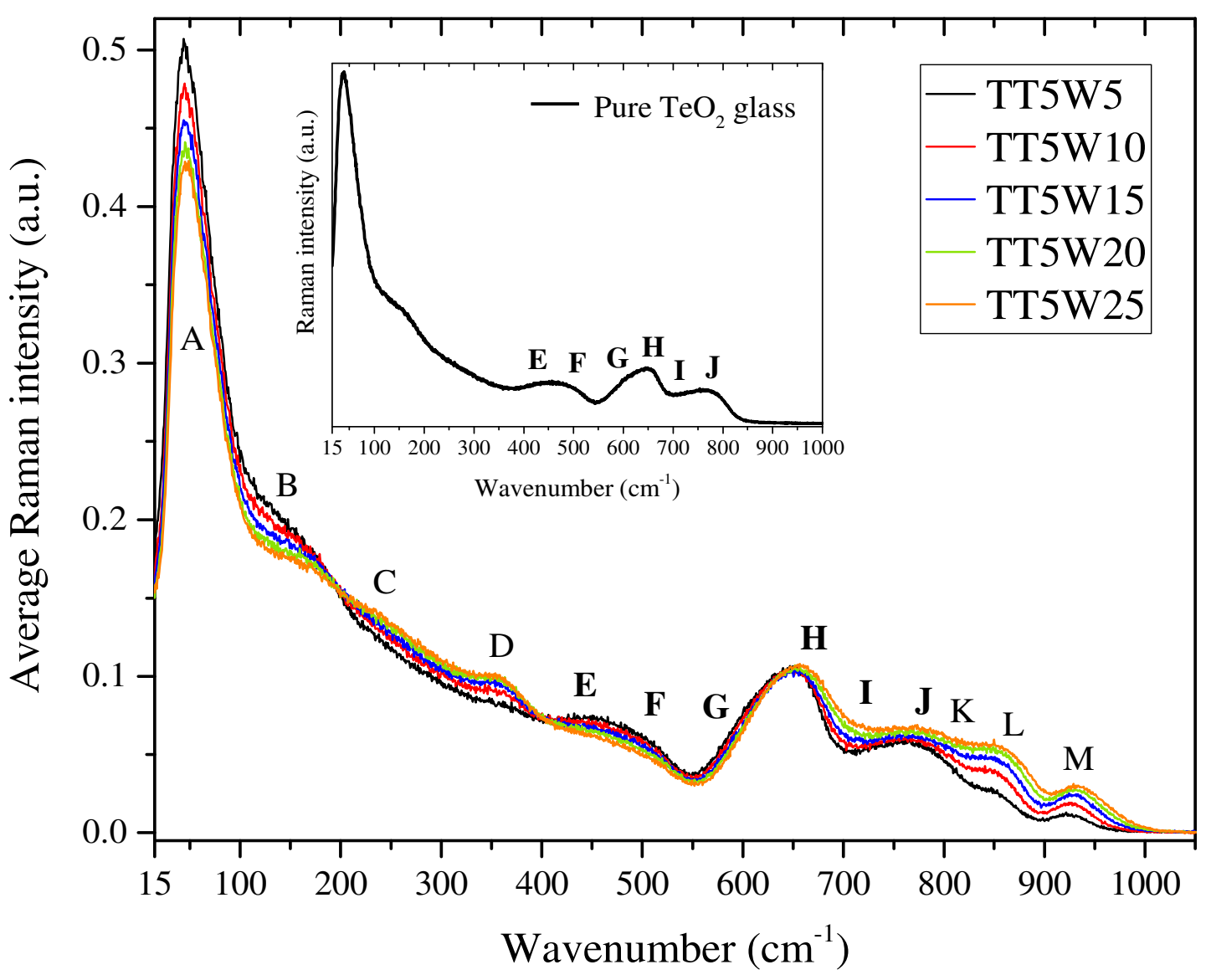




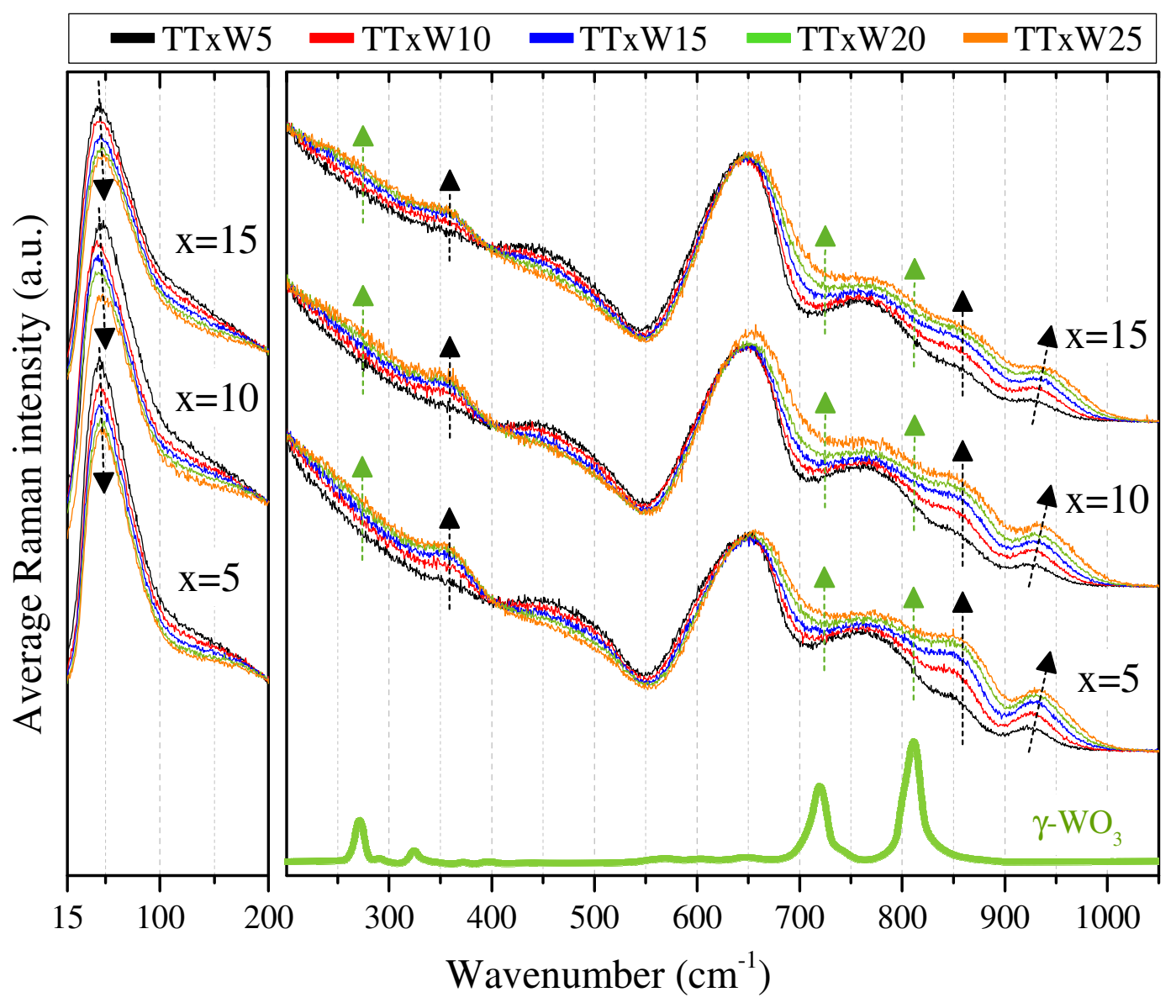




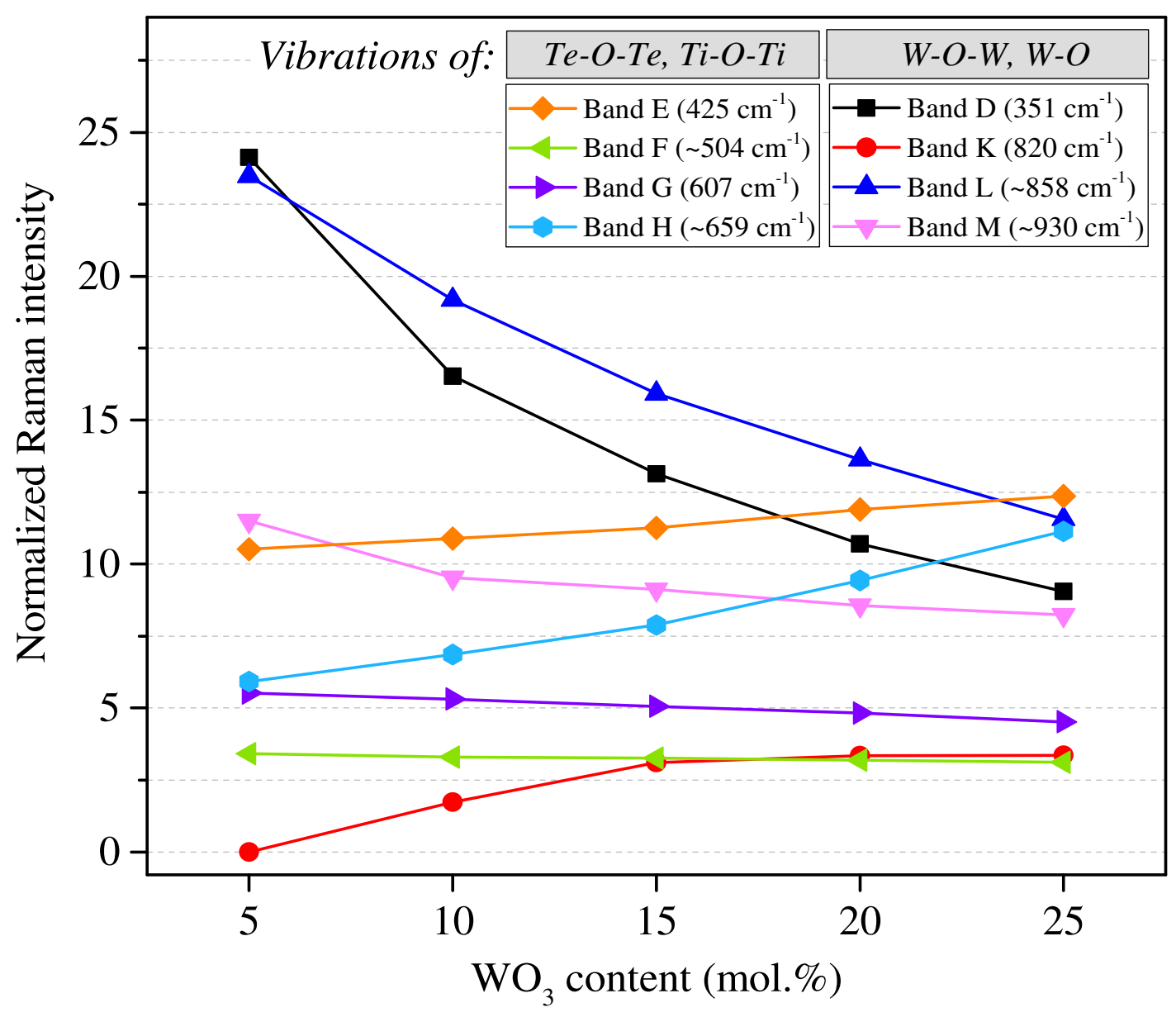



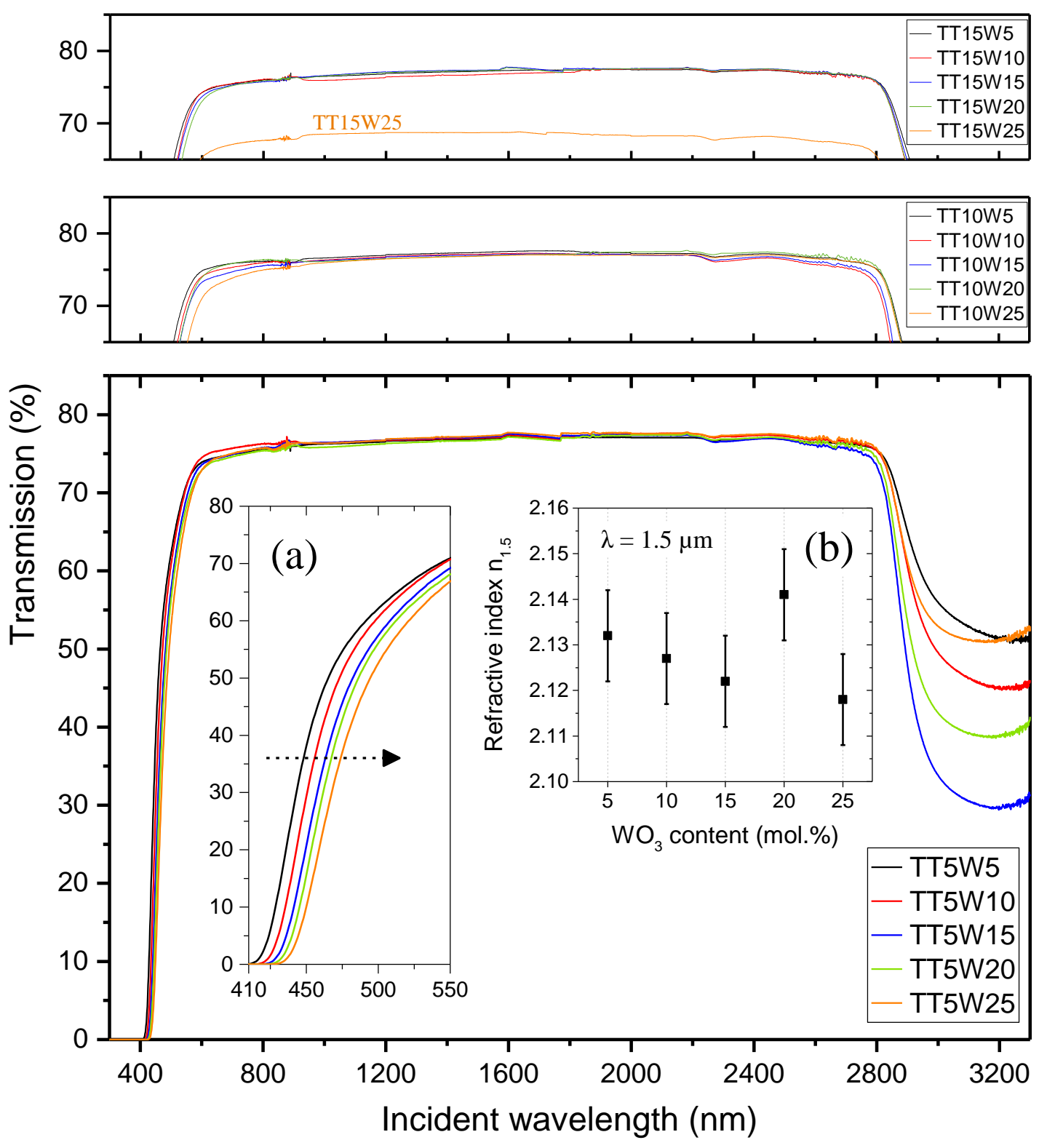

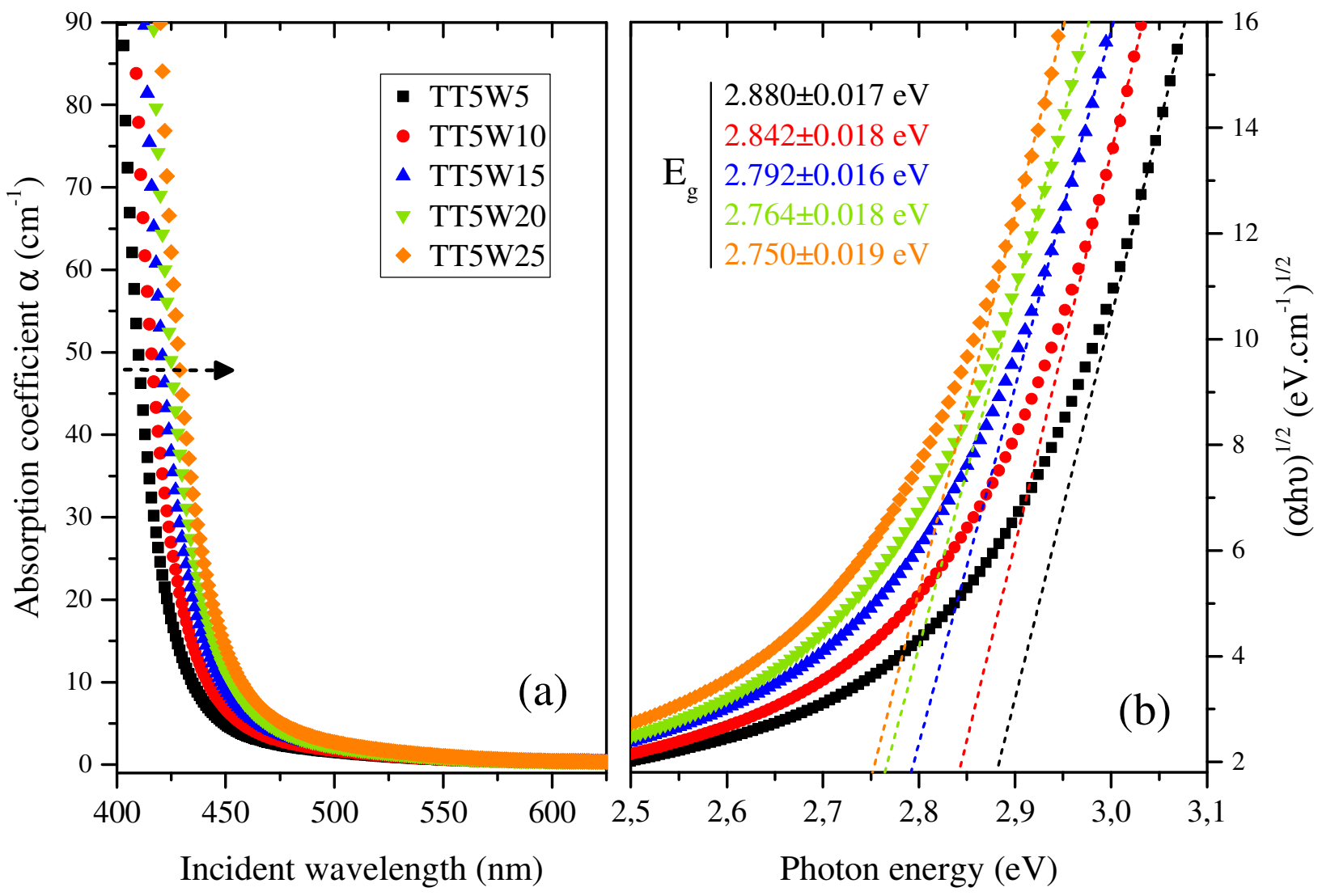


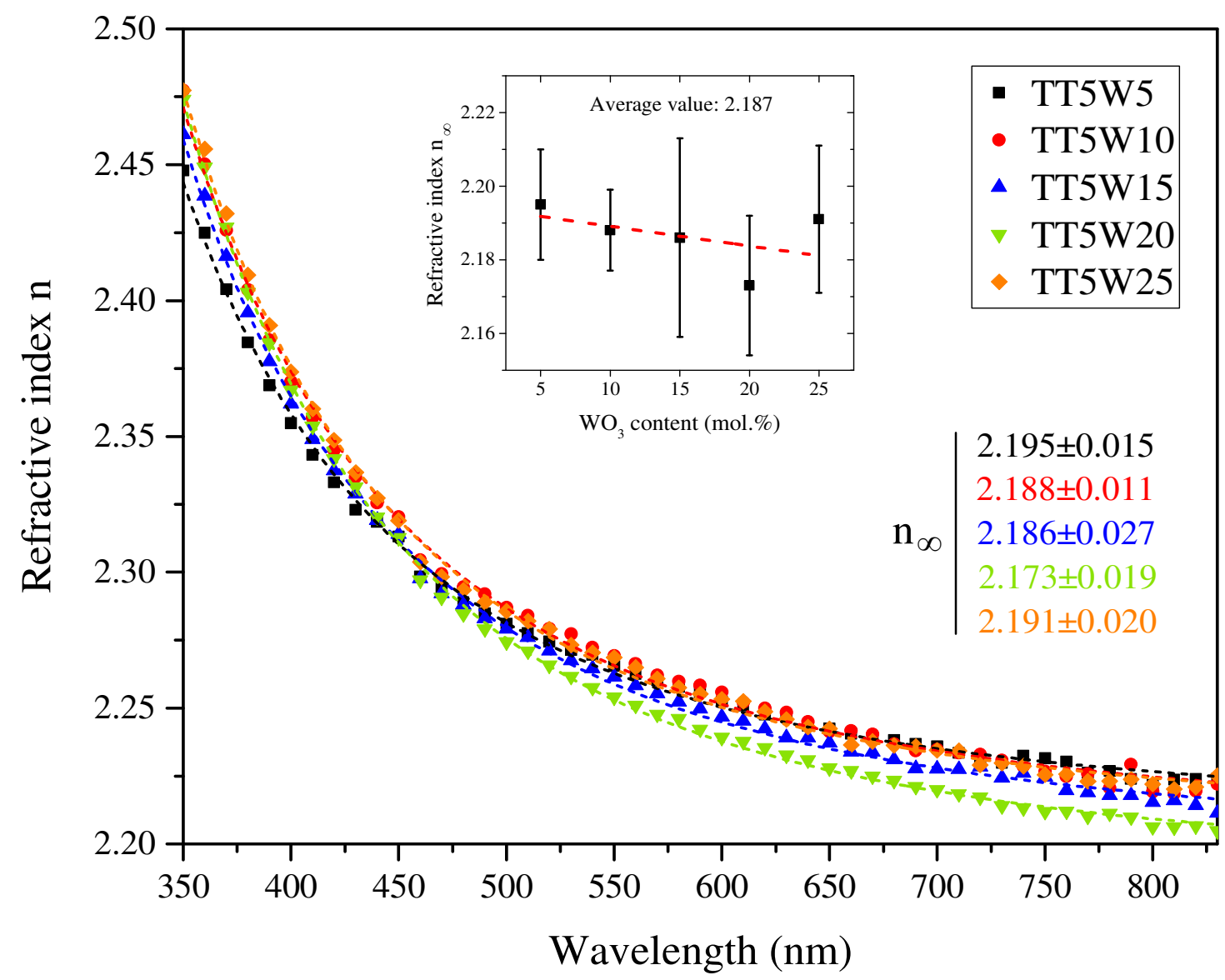

